\title{
Aspectos clave para repensar el derecho de autor en el entorno digital en América Latina
}

Revista Latinoamericana de Economía y Sociedad Digital

Issue 1, agosto 2020

Autores: Sebastián Cabello

DOI: $10.53857 /$ FYHU8212

Publicado: 10 agosto, 2020

Cita sugerida: Cabello, Sebastián (2020) "Aspectos clave para repensar el derecho de autor en el entorno digital en América Latina" en Revista Latinoamericana de Economía y Sociedad Digital, Issue 1

Licencia: Creative Commons Atribución-NoComercial 4.0 Internacional (CC BY-NC 4.0)

Tipo: Análisis de política pública

Palabras clave: Derecho de Autor, Digitalización, Directiva Europea de Derechos de Autor, Economía de la innovación, Economía del conocimiento, Propiedad intelectual, Puerto seguro, Responsabilidad de Intermediarios

\section{Resumen}

El derecho de autor está hoy sujeto a intensos debates a partir de la expansión de los medios digitales, nuevas formas de producción y consumo de contenidos, y el uso de plataformas intermediarias. En particular, a partir de la aprobación de la Directiva Europea 2019/790 de derecho de autor se han creado desafíos contrapuestos en todo el mundo, que tienen su resonancia en América Latina. Por un lado, encontramos a aquellos preocupados por la libertad de expresión en Internet y la innovación. Por otro lado, vemos a los sectores tradicionales de creadores y tenedores de derechos y los medios de prensa quienes buscan nuevos modelos de financiamiento. Este trabajo analiza el marco teórico-conceptual del derecho de autor desde un punto de vista multidisciplinario, con especial énfasis en entender cuál es el óptimo social de control y remuneración justa de los autores para el mundo en desarrollo y América Latina en particular. Se ensaya cómo puede comportarse la oferta y la demanda de creaciones de contenidos y obras en distintos momentos luego de aumentar el control y la remuneración a los creadores. Se observa que el efecto sustitución del incentivo a los creadores es menor que la retracción de la oferta dada en el momento 
inicial, generando una pérdida de bienestar por el mayor control expandido a los intermediarios de Internet. Esto se explica en que en el mundo en desarrollo existe una "des-balanza de pagos" de la propiedad intelectual y numerosas barreras a la entrada e imperfecciones de mercado que afectan negativamente la difusión, creación de contenido local y la innovación. Se proponen cinco aspectos de análisis para tener una visión que aborde apropiadamente el tema y se concluye que, dadas las particularidades de América Latina, la región se vería más beneficiada de un régimen más abierto a la difusión de contenidos, conocimientos y a la innovación, que de uno más restrictivo como el planteado por el modelo europeo en esta materia.

\section{Introducción}

\section{Los nuevos procesos de reforma del derecho de autor y la digitalización acelerada por la COVID-19}

La creciente digitalización de la vida social y económica ha expandido la magnitud y alcance de la producción intelectual y cultural, así como las modalidades de consumo. Este fenómeno, facilitado por la intermediación de plataformas de Internet, está generando enfrentamientos regulatorios con diversas ramificaciones, entre ellas, la del ejercicio del derecho de autor. El rol y la responsabilidad de los intermediarios de Internet, ya sea por la provisión o moderación de contenidos, su veracidad, la provisión de servicios de indexación y búsqueda, o las plataformas de comercio electrónico, pasando por las redes sociales y la compartición de contenidos creados por los usuarios, e incluso los nuevos fenómenos en auge más recientes de transmisiones vivo y juegos en línea, son todos materia de creciente tensión y discusión regulatoria.

Esta tensión se ha visto, por ejemplo, en los debates en torno a las noticias falsas y la moderación de discursos de odio. La confrontación entre la adecuación de la regulación legada o la búsqueda de nuevos modelos ha sido muy patentemente reflejada en la acalorada y polarizada discusión que llevó a la aprobación de una nueva Directiva Europea 2019/790 sobre los derechos de autor en abril de $2019 .{ }^{[1]}$ A lo largo de los dos años subsiguientes, los países miembros de la Unión Europea estarán definiendo su implementación, la cual es de alguna manera incierta porque ha innovado en mecanismos ex ante de bajada y cobro por contenidos que puedan considerarse violatorios, y que no tienen antecedentes en la práctica. Este precedente genera un nuevo estándar, tal como ha sucedido en materia de protección de datos con el Reglamento General de Protección de Datos (RGPD), que plantea disyuntivas que vale la pena evaluar críticamente, en especial para el mundo en desarrollo.

Por si fuera poco, la crisis del coronavirus ha acelerado sustancialmente la relevancia de lo digital, y con ella sus tensiones. Según el Digital News Report 2020 del Instituto Reuters, el consumo de noticias online ha crecido enormemente vis-a-vis el de los diarios impresos, que 
en el último tiempo ha caído más aceleradamente de lo que ya había caído debido a que los confinamientos minaron la distribución física. Según el reporte, solo entre enero y abril de 2020 (ya durante la pandemia) se veía una aceleración de las tendencias de consumo de noticias online $(+2 \%)$ y redes sociales $(+5 \%)$ en promedio por sobre el crecimiento que ya se registraba respecto de 2019. Según el reporte, entre 2017 y 2020, países de la región ya tenían una predominancia de acceso a noticias en línea (todos superiores al 85\% de los encuestados), y por sobre la TV y la prensa (apenas arriba del 20\%). En algunos países como Argentina y México, las redes sociales incluso ya venían superando a la TV como fuente primaria de noticias. Por otro lado, en Brasil y Chile por primera vez en 2020 las redes sociales y los teléfonos inteligentes superaban a la TV.

El uso de medios online y redes sociales como WhatsApp o plataformas de videollamadas como Zoom, Teams y otras creció exponencialmente ante las crecientes necesidades de conectarse, compartir información, participar en una red local de ayuda, trabajar, educarse y entretenerse. Proveerse de información confiable está siendo vital, al igual que dar continuidad a las actividades sociales e individuales. Esto tiene como condición necesaria tener acceso a una conectividad robusta y asequible y, luego, poder contar con plataformas y medios locales, regionales y globales que permitan viabilizar el acceso y la generación de contenidos.

En el estado de excepción en el que todavía se encuentran la mayoría de los países, con variadas disrupciones de actividades económicas y de enforcement de regulaciones y derechos privados que podrían considerarse secundarios ante la emergencia y la preservación de la salud pública, han surgido tensiones sobre la privacidad y, en menor medida, sobre el ejercicio del derecho de autor. Es de esperarse que este último sea un nuevo y variado campo de conflicto entre tenedores de derechos que exigen una remuneración, y nuevos creadores y consumidores que requieran de otros sistemas de distribución asociados con base en Internet. Claramente, si la educación virtual, hoy en emergencia y atravesando una forzada readecuación, va a tener numerosas restricciones relativas al ejercicio de derechos a las ya prevalecientes de acceso a la conectividad y falta de asequibilidad y disponibilidad de contenidos, seguramente no será viable. Por ejemplo, Argentina no tiene reglamentada la excepción para fines educativos del Convenio de Berna, ni los tratados de la Organización Mundial de la Propiedad Intelectual (OMPI, o WIPO por sus siglas en inglés). Legislaciones como esta requieren en muchos casos autorizaciones expresas de los autores y numerosos registros para la reproducción o uso, todavía incluso ninguna legislación considera aspectos distintivos de la educación virtual.

En medio de la pandemia, México aprobó la reforma a la Ley Federal del Derecho de Autor, que entró en vigor el 2 de julio 2020, la cual formaba parte de la armonización legislativa del nuevo Tratado entre México, Estados Unidos y Canadá (TMEC). Esta reforma alineó a México a las provisiones de la Digital Millennium Copyright Act (DMCA por sus siglas en inglés) de los Estados Unidos, quitando responsabilidad a los proveedores de servicios online por las infracciones, estableciendo un mecanismo de notificación y retirada, y 
criminalizando la elusión de medidas tecnológicas de protección (candados digitales). La sociedad civil ha alertado sobre este último punto por considerarla una provisión que es violatoria de la Constitución mexicana y del ejercicio de los derechos humanos. Más allá de que es esperable que esta reforma sufra de variada litigiosidad a la hora de su aplicación, resulta una oportunidad perdida para avanzar en especificidades nuevas que adecuen el régimen imperante del derecho de autor para el mundo cada vez más digital.

Como se analizará seguidamente, el entorno de Internet ha cambiado sustancialmente el modo en el cual se producen y consumen los contenidos y las obras sujetas a derechos. A pesar de esto, en el diseño y la aplicación del régimen de derecho de autor ha predominado un enfoque legalista a favor de los sectores tradicionales (como las sociedades de gestión colectiva y medios establecidos) que no refleja las nuevas necesidades, sectores emergentes y dinámicas del mundo digital. Aquí se argumenta que resulta vital expandir el foco actual en estos regímenes para agregar elementos que reflejen este nuevo macroambiente, para de este modo dar mejor cuenta de los trade off subyacentes de innovación vs. defensa de la propiedad intelectual y de libertad de expresión vs. ejercicio de los derechos de autor. Fundamentalmente, sería importante que el diseño del régimen de derecho de autor esté asociado a un objetivo de política pública de promover el desarrollo de los ecosistemas digitales locales. Las implementaciones de la directiva europea y su posible onda expansiva en América Latina, lo que se da en llamar "Efecto Bruselas" (Bradford 2012), podrían impactar significativamente en el modelo funcional y de uso de Internet tal como lo conocemos en nuestra región. En la práctica, el peligro está en que el ecosistema digital opere de un modo más restrictivo, generando incentivos distorsivos sobre los distintos actores, y, en consecuencia, condicionando la producción, la creación de contenidos y la innovación basadas en lo digital.

Este trabajo se propone contribuir al siempre candente debate regional del rol de los intermediarios tecnológicos de Internet y el ejercicio del derecho de autor, buscando proveer líneas de análisis complementarias a las tradicionales del Derecho, teniendo en cuenta el entorno y la dinámica de Internet a nivel regional. En una primera parte se presenta el caso de la nueva directiva europea que fija un nuevo estándar de protección y se busca analizar sus posibles implicancias si las mismas fueran consideradas un referente regulatorio tal como proponen los medios de prensa ante la caída de sus ingresos publicitarios y las sociedades de gestión de derechos. Luego, se desarrolla un marco teóricoconceptual de análisis para aproximarnos a lo que podría ser el "óptimo social" de aplicación del derecho de autor a nivel regional. En tercer lugar, se analizan varios aspectos distintivos que caracterizan la situación del derecho de autor en la región y que respaldan esa conceptualización "sub-óptima" de la región vis-a-vis los ecosistemas digitales más desarrollados. Estos abordajes serán de utilidad a la hora de aproximar futuros cambios legislativos o regulatorios que atiendan a la modernización de los regímenes vigentes a fin de que no estén movilizados solo por intereses unidireccionales, disociados del impacto que estos puedan tener sobre el consumo, los medios de producción, sus cadenas de valor y la innovación en el ecosistema digital latinoamericano. 


\section{La reciente directiva europea sobre derechos de autor fija un nuevo estándar}

La nueva Directiva Europea 2019/790 sobre los derechos de autor y derechos afines en el mercado único digital fue aprobada el 17 de abril de 2019 y publicada el 17 de mayo del mismo año ${ }^{[2]}$, modificando así las Directivas 96/9/CE y 2001/29/CE. Esta norma apunta principalmente a fijar reglas más estrictas de responsabilidad respecto al uso y circulación de contenidos por los intermediarios de Internet, revirtiendo la carga de la prueba de lo que se consideraba el "puerto seguro" para los proveedores de internet, expresado tanto en la Directiva Europea de Comercio Electrónico de 2000 y la DMCA de 1998. ${ }^{[3]}$ Hasta el momento, los tenedores de derechos eran quienes tenían la carga de descubrir violaciones y solicitar "su retirada" mediante intervención judicial. En la nueva directiva hay dos medidas en particular que, en función de cómo se reglamenten e implementen a nivel de los estados nacionales, podrían constituir elementos "que cambien el juego" en la Internet que conocemos hoy:

\section{- Artículo 15. Cobro a los servicios online por el uso de extractos cortos del} contenido periodístico. Aquí se apunta sobre todo a buscadores y agregadores de noticias que muestran vistas previas de artículos de prensa, aunque lo mismo sucede con los fragmentos que incluyen redes sociales cuando se comparte una dirección web. ${ }^{[4]}$

\section{- Artículo 17. Creación de un mercado de licencias y responsabilidad entre los propietarios de derechos y los servicios online que los pongan a disposición. La} propuesta es que los autores individuales o sociedades de gestión colectiva de derechos puedan reclamar que los sitios de comunidades y redes sociales paguen por la difusión de material con derechos de autor por parte de sus usuarios o caso contrario prohíban la circulación de contenido protegido. Los servicios online pasan a ser responsables por la circulación de material protegido en sus entornos, salvo que demuestren haber hecho lo máximo posible para intentar evitarlo, con el ejercicio de las mejores prácticas y tecnología disponibles. $^{[5]}$

El derecho de autor aquí pareciera adquirir una predominancia que entra en contraposición con derechos humanos de mayor orden axiológico como la libertad de expresión, algo que ampliamente han señalado con preocupación durante los debates europeos, por ejemplo, el Relator Especial sobre la promoción y protección del derecho a la libertad de opinión y expresión de las Naciones Unidas, David Kaye ${ }^{[6]}$, o diversas organizaciones defensoras de la libertad en Internet ${ }^{[7]}$. Entre los riesgos apuntados se encuentra el posible impulso a la censura previa por parte de las compañías de Internet, que busquen protegerse de manera preventiva mediante la implementación de algoritmos de filtrado automático antes de aceptar la publicación de algún contenido a fin de evitar ser declaradas responsables por infracciones a la propiedad intelectual o de ser sujetas al pago de derechos. 
Las organizaciones de la sociedad civil en América Latina han seguido estos devenires con preocupación destacando que, si bien el Sistema Interamericano de Derechos Humanos prohíbe la censura previa, las decisiones tomadas en Europa muy probablemente impondrán de facto un nuevo estándar por el que los servicios globales se empiecen a diseñar según esa norma aplicada a todas las jurisdicciones para evitar la responsabilidad ${ }^{[8]}$. Por ejemplo, el reclamo del Consorcio "Al Sur" de abril de 2019 fue muy fuerte: "la censura previa se convertirá en la regla que cambia nuestro marco legal sin que nosotros participemos en él". Es interesante destacar que estas organizaciones suelen también ser críticas de la regulación privada de contenidos por parte de las plataformas y su predominancia, pero tienden a coincidir en torno a la exención de la responsabilidad de los intermediarios y las limitaciones a la libertad de expresión que trae el ejercicio tradicional del derecho de autor aplicado al mundo digital.

Sin embargo, la medida europea ha sido promovida por las sociedades de gestión colectiva (SGC) de autores y por la Sociedad Interamericana de Prensa (SIP), que ha expresado su satisfacción con lo resuelto y recomendado a los países de la región latinoamericana promover iniciativas en esa dirección. La SIP y las asociaciones nacionales de prensa ${ }^{[9]}$ entienden esta medida como necesaria para dar sostenibilidad a la actividad editorial debido a que el sector hoy sufre de un achicamiento como consecuencia del cambio en el paradigma de consumo (y producción) de contenidos. Este hecho tiene, a su vez, efectos significativos sobre la forma de comercialización del periodismo y ha dado lugar a una nueva dinámica del mercado de la publicidad. Al mismo tiempo, la propia SIP ha dado cuenta de la problemática del debate europeo y los reclamos de la sociedad civil al incluir en su declaración de principios de octubre de $2018{ }^{[10]}$ que "los actores del ecosistema digital deben lograr un balance adecuado entre la libertad de expresión, los derechos de autor y la propiedad intelectual, así como respecto a los beneficios que puedan generar los contenidos en dicho ecosistema".

A raíz de las discrepancias entre los argumentos esgrimidos por los distintos autores, se analizan a continuación las implicancias que podrían tener estos nuevos estándares de protección de derechos de autor para los regímenes latinoamericanos, lo que también se da en llamar "efecto Bruselas" (Bradford 2012) extendido a los derechos de autor. Aquí se señala una diferencia sustancial con lo que sucede en torno al RGPD, del cual existe mayor consenso y es mayoritariamente un modelo para seguir en las reformas regionales hoy asociadas al interés de casi todos los países de obtener el "estatus de regulación adecuada" a la Unión Europea.

\section{Aproximaciones teórico-conceptuales al "óptimo social” de aplicación del derecho de autor en américa latina}

En virtud del Tratado de la Organización Mundial de la Propiedad Intelectual (OMPI) sobre Derecho de Autor (WCT 1996), el derecho de autor se consagra a las creaciones literarias y artísticas como los libros, las obras musicales, las pinturas, las esculturas, las películas y las 
obras realizadas por medios tecnológicos como los programas informáticos y las bases de datos electrónicas. El derecho de autor protege dos tipos de derechos: por un lado, los derechos patrimoniales, que permiten a los titulares de derechos percibir una retribución económica en caso de que terceros utilicen sus obras. Por otro lado, los derechos morales permiten que el autor o el creador tome determinadas medidas para preservar y proteger los vínculos que los unen a sus obras.

Internet se ha vuelto una plataforma vital para promover el acceso a contenidos como películas, música, libros, noticias y software. Esto ha sido gracias a que Internet ha bajado las barreras de acceso: por eso, hoy se puede acceder con inmediatez a contenidos expandiendo considerablemente el mercado y el consumo. A medida que la tecnología evoluciona y se hace más portable e individualizada, los sectores productores de contenido han tenido que evolucionar y apoyarse en nuevos y más innovadores modelos de negocios basados cada vez más en Internet. Estudios de la Organización para la Cooperación y el Desarrollo Económicos (OCDE) y la OMPI sobre el sector intensivo en derechos de autor a principios de esta década muestran que, aunque esta transformación ha tenido costos, como puede ser la piratería, el desempeño del sector es positivo en términos de creación de valor y empleo, el cual representa alrededor del 5\% del PIB en las economías más avanzadas (OCDE 2015).

La teoría económica del derecho de autor se ha apoyado en que los bienes creativos son un tipo de bien público debido a que suelen tener características de "no rivalidad" (pueden ser usados por muchas personas al mismo tiempo sin afectar su disponibilidad) y son "no exclusivos" (no es posible impedir que una persona cualquiera pueda consumirlo). La protección del derecho de autor se cree necesaria para evitar la copia no autorizada 0 piratería, y que así existan incentivos para desarrollar nuevos bienes, ya que básicamente son bienes difíciles de crear pero fáciles de copiar. Aquí, el "elemento transado" en un intercambio de material sujeto a derechos de autor es el derecho de acceso o uso, pero no la propiedad misma. Al mismo tiempo, también se destaca el trade off de que la protección excesiva crea poder monopólico de mercado y, en consecuencia, precios más altos, menor acceso y difusión de las obras. Por lo tanto, el punto clave es lograr el balance adecuado entre el incentivo a la creación y producción de contenido y el acceso. En la Tabla 1 a continuación puede verse una conceptualización estilizada del comportamiento de la oferta y la demanda de la aplicación del derecho de autor y de los costos administrativos de su aplicación.

Tabla 1: Modelo conceptual de la aplicación de derechos de autor 


\begin{tabular}{|c|c|c|}
\hline Efectos & Positivos & Negativos \\
\hline Oferta & $\begin{array}{l}\text { - Soluciona falla de mercado } \\
\text { de no exclusividad y no } \\
\text { rivalidad } \\
\text { - Aumenta incentivos a } \\
\text { crear/producir al aumentar } \\
\text { su remuneración } \\
\text { (especialmente para sectores } \\
\text { tradicionales) }\end{array}$ & $\begin{array}{l}\text { - Promueve la búsqueda de } \\
\text { renta monopólica (aumenta } \\
\text { costos de producción, } \\
\text { discriminación de precios) } \\
\text { - Reduce la innovación al } \\
\text { limitar la difusión de obras que } \\
\text { pueden servir a nuevos } \\
\text { creadores (adaptaciones, } \\
\text { reúsos) }\end{array}$ \\
\hline Demanda & $\begin{array}{l}\text { - Aumenta la producción de } \\
\text { actores existentes }\end{array}$ & $\begin{array}{l}\text { - Reduce el acceso a obras, } \\
\text { reduce el bienestar social }\end{array}$ \\
\hline Administrativos & $\begin{array}{l}\text { - Establece un mecanismo de } \\
\text { transacción y compensación }\end{array}$ & $\begin{array}{l}\text { - Aumenta los costos de la } \\
\text { protección, intermediación y } \\
\text { disputabilidad. } \\
\text { - Pérdida de eficiencia al } \\
\text { financiar estructuras que } \\
\text { reducen retribución }\end{array}$ \\
\hline
\end{tabular}

Fuente: elaboración propia. Adaptado de Wunsch-Vincent (2016).

El consenso de pensamiento de política económica en torno a la legislación en materia de derecho de autor en los países desarrollados ha sido que esta sea utilizada con el fin de maximizar la innovación y la creatividad. De este modo se produjeron las adaptaciones regulatorias pioneras reflejando el pasaje del mundo físico al digital, empezando con la DMCA de 1998, la Directiva Europea anterior de 2001, legislación del Reino Unido en 2010, Canadá en 2012, y Australia en 2017, entre varias otras. Todas estas normativas se han apoyado en el concepto de "puerto seguro".

En América Latina hay mucha disparidad normativa: se destacan regulaciones como la de Colombia (1982), Brasil (1998), México (2003 reformada en 2020) y Chile (2010), que también ha avanzado en el tema con varios acuerdos comerciales internacionales. El caso extremo de antigüedad es quizás el de Argentina, cuyo cuerpo normativo central data de 1933. Es interesante destacar que, en los últimos setenta años, cada vez que se han hecho reformas han sido para aumentar el plazo de protección de las obras previniendo que pasen al dominio público. Hoy el plazo estándar en la región es de 50 años después de la muerte del autor, con casos extremos como en México, donde es de 100 -plazo de que no fue 
reformado en 2020- y en Argentina, 70 años.

Existen diferentes visiones sobre cuál debería ser el nivel "óptimo" de control del derecho de autor en la era digital. Por un lado, ha surgido recientemente mucha literatura con una visión revisionista y crítica al enfoque tradicional basada en el argumento de que el aumento de la protección al derecho de autor no produce necesariamente mayor creación de obras ya que tiene un efecto mixto sobre los incentivos de los creadores de contenido ${ }^{[11]}$.

Quienes proponen estas ideas sostienen que, del lado de la oferta (creación de contenido), reforzar el control y/o aumentar el cobro de los derechos de autor beneficia más a los creadores establecidos que a los nuevos, aumentando las barreras de entrada. Esto se debe a que reduce la demanda de nuevas producciones porque hace que los nuevos actores tengan que dedicar más tiempo a la creación hasta percibir ingresos (Watt 2013) ${ }^{[12]}$. Esta barrera se manifiesta de manera aún mayor en países en desarrollo donde la demanda es más baja que en los países desarrollados por cuanto existe menor disposición a pagar por productos con derechos. La idea básica de la teoría es que, en la búsqueda por obtener el óptimo social deseable de protección del derecho de autor, un aumento de medidas controlantes baja la demanda y solo puede ser compensada si aumenta la oferta de producción (Wunsch-Vincent 2016). Aquí la evidencia empírica es pobre y limitada (Watt 2013) y, hasta el momento, no se ha demostrado que aumentos en la exigencia de derechos tengan real impacto en aumentos en la producción que sobrepasen la caída demostrable de la demanda (es decir, el efecto sustitución no es directo).

Por otro lado, autores como Liebowitz (2018), en un estudio para la Confederación Internacional de Sociedades de Autores y Compositores (CISAC), han sostenido que las medidas de "puerto seguro" limitan o condicionan la responsabilidad de los intermediarios de Internet distorsionando los mercados digitales. Según este argumento el contenido subido por el usuario (UUC por sus siglas en inglés) hace uso de obras directas o derivadas sujetas a derechos que no son pagados debidamente a los tenedores de derechos y que son monetizadas por los gigantes de Internet. De este modo se propone ir más allá del modelo actual de "notificación y retirada" para extender las responsabilidades de los intermediarios y aumentar los mecanismos de cobro de derechos. Este trabajo y sus postulados han sido bastante criticados por otros autores como Elkin-Koren, Nahmias, Perel (2019) porque no proveen evidencia alguna de que invertir la carga de la prueba del puerto seguro, es decir, al reforzar la exigencia del derecho de autor traspasándole el rol de control y cobro a los intermediarios, cambie la situación de su sector, ya que esta se debe a cambios sociales y la calidad de los productos ofrecidos y que, además, el bienestar social se va a ver reducido. ${ }^{[13]}$

Cabe destacar que proteger que no existan copias no autorizadas o falsificaciones, también conocido como el acto de piratería, es un hecho bien distinto al de diseñar nuevos mecanismos de remuneración abusivos. Esto es lo que parece suceder en muchos casos en las SGC, que actúan de facto de manera monopólica sobre todo tipo de creaciones, incluso aquellas ajenas a sus afiliados (Botero et. al 2015). La gestión de derechos en forma 
exclusiva está inclusive habilitada en la legislación de países como Argentina y Uruguay. Una extensiva investigación sobre las SGC dedicadas a la gestión de derechos en América Latina liderada por la Fundación Karisma en 2015 ha dado cuenta de la opacidad de gobernanza, reporte y control de las SGC, así como de la arbitrariedad en la fijación de reglas respecto de quién debe pagar y la forma de distribución de lo recaudado. Esta situación, sumado a los requisitos fijados para que puedan constituirse nuevas SGC, constituye una clara barrera a la entrada para los nuevos creadores, más aún de los creadores y artistas nativos digitales. Debe analizarse si las ventajas para las SGC (en relación con eficiencia y precio, por ejemplo) suponen desventajas similares en la medida en que se estaría formando un monopolio (cártel) que obligaría a todo creador de la región a utilizar el mismo intermediario, disminuyendo considerablemente sus opciones en el mercado, especialmente para los más pequeños, nuevos y/o independientes. ${ }^{[14]}$

Para trascender a estas visiones enfrentadas, puede ser útil intentar otros abordajes que nos permitan buscar cuál sería el "óptimo social" de la aplicación del derecho de autor que deba aplicarse a la hora de definir un régimen normativo. Esto sería necesario para balancear la remuneración y sostenibilidad de los creadores existentes con el acceso y la innovación y que, a su vez, tenga en cuenta el interés público. ${ }^{[15]} \mathrm{Tal}$ como lo señalan expertos en la materia como Watt (2009), esta búsqueda es necesariamente distinta para los países desarrollados que para aquellos en desarrollo, ya que la estructura de demanda y oferta es distinta. La regulación de la propiedad intelectual y, en consecuencia, el derecho de autor debería ajustarse a la realidad social, económica y cultural que tengan esos países, amén de los objetivos de política pública que alguna administración en particular persiga.

A continuación, a los efectos de modelizar este trade off, y siguiendo con estas aproximaciones conceptuales podríamos esperar que el efecto de aumentar las exigencias del derecho de autor produzca una retracción de la oferta de contenidos (ver Gráfica 1). En efecto, la inversión de la carga de la prueba al llamado "puerto seguro", limitando las vistas previas y promoviendo el filtrado ex ante al estilo europeo, tendría efectos restrictivos para el acceso de las audiencias, promoviendo la censura preventiva, errores en el filtrado automático en la identificación de obras originales o derivadas, limitando la difusión de contenidos y, por ende, la innovación. Esto se manifestaría aumentando las barreras a la entrada para el desarrollo de nuevos creadores que van a verse limitados a usar plataformas de Internet para la difusión de sus obras.

Gráfica 1: Los trade-off de los derechos de autor en el mundo en desarrollo 
Momento 1: Retracción de la Oferta

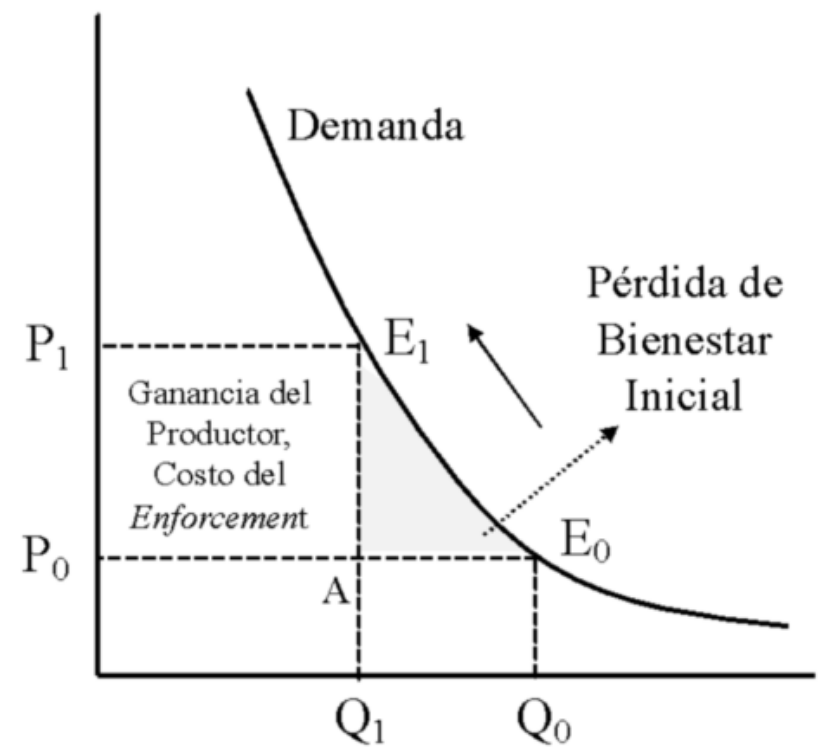

Momento 2: Aumento de la Oferta

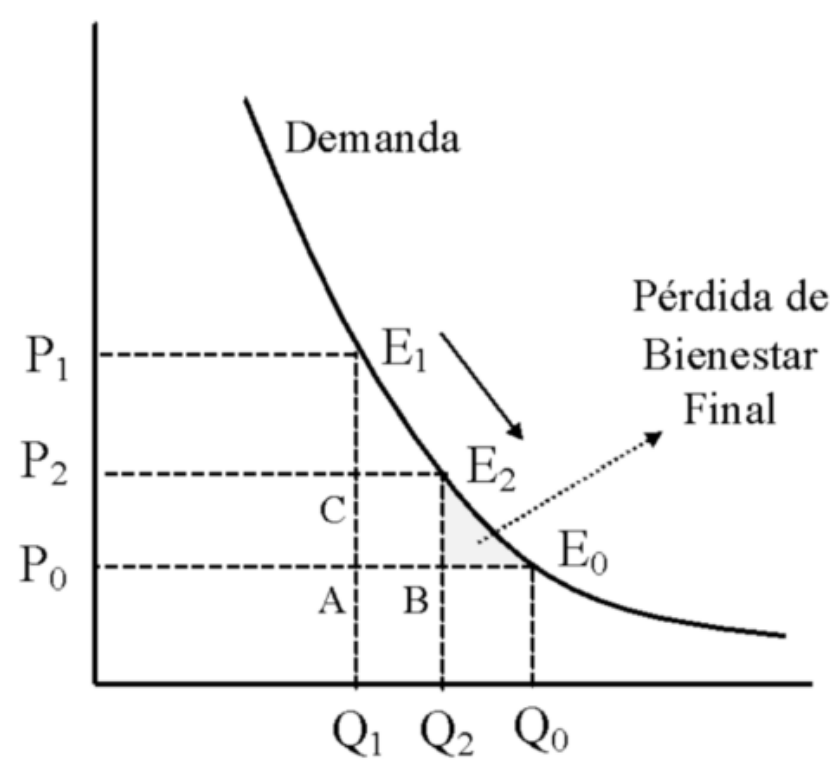

Fuente: elaboración propia.

Tal como se muestra en la Gráfica 1, se esperaría entonces que en un Momento 1 hubiera una retracción de la Oferta de contenidos disponibles, que implica un aumento de precios dados por

las restricciones y las mayores compensaciones a los creadores, medios y sociedades colectivas. Esto puede visualizarse a través de un desplazamiento a lo largo de la Demanda pasando de un equilibrio E0 a E1. El desplazamiento hacia la izquierda de la Oferta también se explica por el aumento del control y remuneración de los bienes sujetos a derechos, lo que generaría mayores costos de producción/distribución, resultando en menos unidades consumidas a un mayor precio. ${ }^{[16]}$ En este Momento 1 y ante una demanda normal decreciente, caerían las cantidades consumidas por las audiencias de Q0 a Q1 y habría una pérdida de bienestar explicada por A-E0-E1.

En un Momento 2, y siguiendo la teoría tradicional, la mayor remuneración a los creadores de bienes sujetos a derechos establecidos a través de sus SGC crearía, luego de un rezago, un efecto de sustitución a la retracción inicial mediante el incentivo a que creen más obras, aumentando la Oferta, estimulando la competencia y produciendo una caída de precios y controles de P1 a P2. Esta caída desplazaría el consumo de Q1 a Q2, llevando a un nuevo equilibrio con la demanda de las audiencias de E1 a E2. Luego, entrarían a jugar aquí las limitaciones intrínsecas para el desarrollo de contenido, creaciones locales y fallas de mercado que impedirían llegar a los valores originales de equilibrio y consumo antes de la implementación de medidas (E0).

Como veremos a continuación, esta situación es la que más claramente podría manifestarse en países en desarrollo como los de América Latina debido a: (i) la presencia de mercados 
concentrados u oligopólicos; (ii) menor tamaño de mercado o capacidad de consumo que no justifique invertir en creaciones y nuevos medios; (iii) los medios y SGC opacas que cobran indiscriminadamente a favor de actores existentes sin que nada se destine a los nuevos medios y creadores; (iv) la brecha de conectividad y de velocidades de Internet para la difusión de creaciones o acceso a mercados; (v) la falta de condiciones educativas o habilidades; (vi) barreras administrativas e impositivas, altos costos, falta de incentivos a la innovación, entre otros. Esto nos lleva a pensar que, a pesar de que pueda haber un efecto de mejora posterior con mayores medidas de control y remuneración a los creadores, este va a actuar con un retraso significativo por las ineficiencias sistémicas y los costos administrativos, el cual difícilmente compensará las pérdidas generales de modo de producir una ganancia de bienestar social.

Es de esperarse que exista entonces una pérdida de bienestar final que estaría comprendida por el área B-E0-E2. Como se ejemplifica seguidamente, este fenómeno también se explicaría no solo por una concentración de la riqueza por la mayor remuneración a actores establecidos, sino también por una salida de capitales por el pago de derechos a todos los tenedores extranjeros, los cuales, en la mayoría del mundo en desarrollo, superan varias veces a los creadores o tenedores de derechos nacionales (en el caso de América Latina, 8,1 veces, tal como se destaca en la sección siguiente).

\section{Aspectos distintivos del derecho de autor en el entorno digital en América Latina}

A continuación, se analizan cinco aspectos distintivos del derecho de autor en el entorno digital en América Latina: la sostenibilidad de los medios de prensa; la retribución "justa" a los creadores y trabajadores; la disponibilidad de información de calidad y los límites a la libertad de expresión; el crecimiento y predominancia de las plataformas; y, por último, el impacto en la innovación y producción de contenidos. Todos ellos permiten validar la conceptualización de Oferta y Demanda de creaciones digitales a nivel regional (Tabla 1 y Gráfica 1) y su posible grado de respuesta e impacto de pérdida de bienestar ante aumentos en las restricciones al intercambio y consumo analizadas en la sección anterior. Su comprensión y valoración multidisciplinaria es fundamental para repensar el derecho de autor en el entorno digital de América Latina.

\section{Sostenibilidad de los medios de prensa}

La llamada revolución digital modificó el modo de distribución, producción y consumo de noticias, así como también la relación con sus audiencias. Se ha observado un aumento sustancial en la oferta de contenidos en distintos formatos que ha afectado los ingresos de las publicaciones tradicionales, algunas consolidándose, otras expandiendo su alcance ${ }^{[17]}$, al tiempo que han aparecido nuevos medios totalmente "nativos digitales".

En Internet, las noticias compiten contra distintos paquetes de contenidos audiovisuales, como los que ofrecen las plataformas de música y video. Algunos estudios muestran que los jóvenes pueden llegar a tener un consumo incidental de noticias, es decir, que llegan a las 
notas de prensa sin haberlo buscado y por medio de su navegación en redes sociales u otros servicios online (Boczkowski, Matassi, Mitchelstein 2017 ${ }^{[18]}$. Por ejemplo, el Digital News Report 2019 del Instituto Reuters menciona que en la región las personas usan las redes para acceder a noticias como vía privilegiada, seguidas por los buscadores en línea. Estos medios digitales proveen un camino alternativo y agregan demanda porque suman lectores que nunca hubieran ingresado directamente a un sitio de los editores de prensa. Si la mitad de las visitas de los medios llega por buscadores, agregadores o redes sociales, tal como lo muestra la Gráfica 2, significa que estos servicios ayudan a generar la mitad de los ingresos por publicidad online de los productores. ${ }^{[19]}$

Gráfica 2: Principal vía de acceso a noticias en 2018

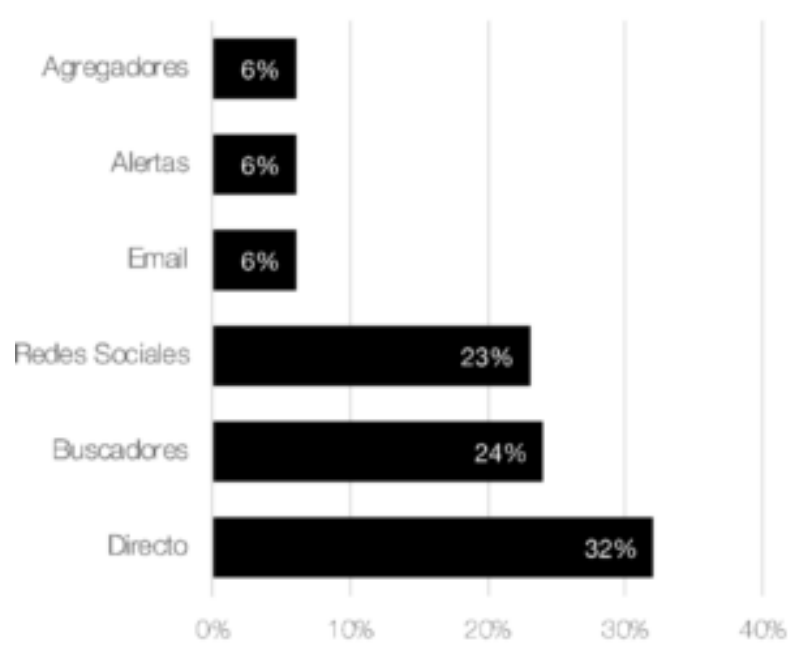

Nota: Datos correspondientes a 37 países de América, Europa, Asia y Oceanía. Los valores no suman 100 por el redondeo.

Fuente: Reuters Institute 2019.

Aquí vemos entonces un doble efecto. Por un lado, la pérdida de relevancia del modo en el cual los medios tradicionales comunican, con su consecuente migración de la publicidad a otros tipos de contenidos. Por otro lado, la expansión de la digitalización también les lleva tráfico que ellos pueden monetizar de acuerdo con el modelo de uso que propongan a sus lectores.

El mercado publicitario en América Latina no es ajeno a la transición global hacia lo digital. Los medios vienen ensayando modelos de monetización en Internet y con base en las redes sociales, que van desde la publicidad online hasta el uso de "paywalls" o muros de pago ${ }^{[20]}$. Si bien las nuevas alternativas no han podido compensar todavía la caída de las versiones impresas, el mercado de la publicidad se está transformando, pero sigue creciendo y brindando opciones de capitalizarlo: estimaciones de Arthur D. Little (2018) pronostican aumentos en la publicidad online a un promedio del 15,4\% anual hasta 2020 inclusive. La inversión publicitaria está cayendo en los medios tradicionales (diarios y revistas) yendo hacia lo digital y particularmente hacia el mundo móvil, donde se concentra el consumo 
actual de contenidos. Las estimaciones de consultoras como eMarketer muestran que en 2018 el móvil representaba $54,6 \%$ del total de publicidad digital y que llegará a ser el $81 \%$ hacia 2023 (Ceurvels 2019). ${ }^{[21]}$

Gráfica 3: Participación de los medios digitales en mercado total de la publicidad en América Latina

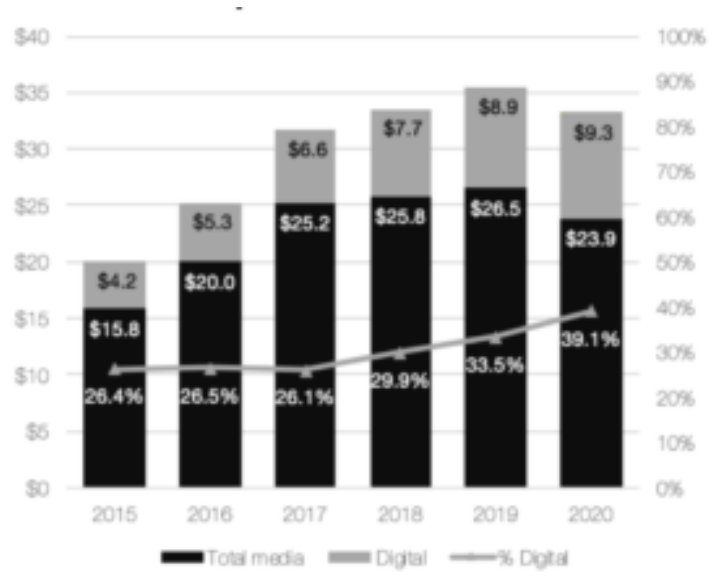

Nota: Tradicional incluye guías telefónicas, revistas, diarios, al hogar, radio y TV. Digital incluye publicidad en laptops, desktops, móviles. tabletas y otros dispositivos conectados incluidos mensajería instantánea. Valores en US\$ mil millones.

Fuente: eMarketer 2020.

Las estimaciones de consultoras como eMarketer consideran que lo digital seguirá creciendo hasta representar casi un 40\% del mercado total latinoamericano, algo que probablemente se verá aún más incrementado a raíz de la caída en inversión publicitaria en general a consecuencia por los efectos económicos de la COVID-19 ${ }^{[22]}$. Dicha consultora estima que la caída en inversión publicitaria total en esta región será de un 10\% para 2020, en tanto que se prevé que crezca la digital un $5 \%$ en $2020^{[23]}$. De cualquier modo, es relevante destacar que América Latina parece encontrarse en un estado todavía muy inicial respecto de la publicidad digital, la cual participaba solo en un 33,5\% del total regional (US\$ 8,9 mil millones) en 2019 (ver Gráfica 3). Algunas razones de la todavía menor participación relativa regional pueden encontrarse en la todavía persistente brecha de conectividad (la penetración de Internet no llegaba al 69\% a mayo 2020, contra casi un 95\% en América del Norte, el 87\% en Europa, y el 70\% en Medio Oriente) ${ }^{[24]}$.

En cualquier caso, el sector de prensa sufre una transición en su modelo de negocios y se encuentra en una lucha por retener la renta publicitaria. Lo que no parece tan claro es que pueda o deba lograrlo mediante regulación, con restricciones a vincular o proveer vistas previas en plataformas y redes, como parece proponerse desde el viejo continente, medidas que -por otra parte- pueden afectar una vía de acceso a sus contenidos. Esta vía de acceso resulta fundamental para los medios más pequeños o nuevas propuestas que no cuentan con el conocimiento de los medios tradicionales, con lo cual regularlo sería equivalente a 
promover mayores barreras a la entrada. ${ }^{[25]}$

\section{Retribución "justa" a los creadores y trabajadores}

Uno de los argumentos para imponer regulaciones más estrictas sobre derechos de autor se basa en la necesidad de garantizar que los creadores reciban una remuneración "adecuada" por sus obras. ${ }^{[2]}$ En muchos casos se argumenta que la facilidad con la que las redes sociales permiten compartir y consumir contenido con derechos de autor hace que los titulares pierdan la posibilidad de obtener una retribución.

Aun así, el sector productor de contenidos está en medio de transformaciones que no evidencian una pérdida de tamaño, y de hecho el medio digital es parte del motor que impulsa su crecimiento. En 2018 la recaudación de copyright en todo el mundo creció 0,9\% y alcanzó los 9.650 millones de euros, con un aumento acumulado del 25,4\% desde 2014, como muestran los datos del último Informe Global de Recaudación de CISAC 2019. ${ }^{[27]}$ Según el reporte, "las fuentes tradicionales se mantienen sólidas" con un incremento de 653 millones de euros con respecto a 2014, mientras los ingresos de derechos de autor digitales son los que direccionan la tendencia, con un crecimiento solo en 2018 del 29\% y de 1.000 millones de euros en esos cinco años. En 2014 el sector representaba el 7,5\% del total y pasó a ser el 17\% en 2018. Esto es particularmente notable en América Latina: el sector digital tuvo un aumento del 49\% en 2018 y del 981\% acumulado en los últimos cinco años. Si bien en la región la proporción es menor $(14,4 \%)$, la participación digital se va acercando al promedio mundial, con casos excepcionales como México donde representa casi la mitad de lo recaudado.

\section{Gráfica 4: Derechos recaudados en \% del PIB regional en 2018}
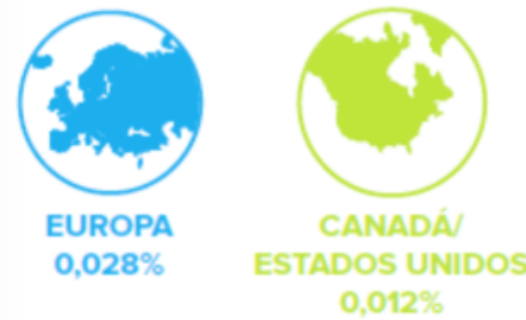

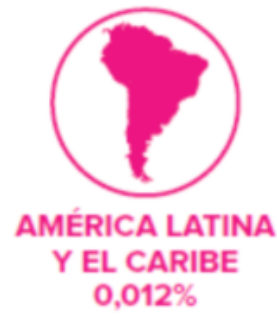

$0,012 \%$
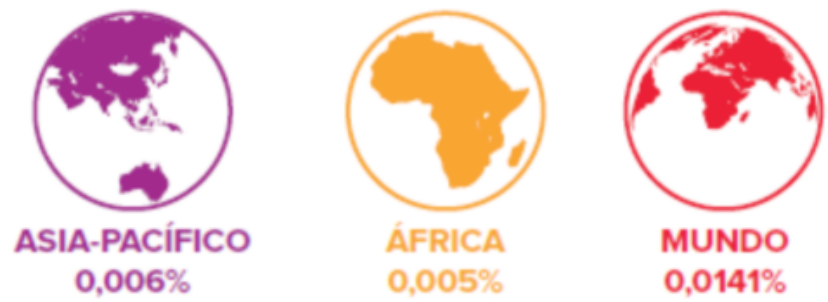

Fuente: CISAC 2019.

América Latina tampoco aparece con una baja recaudación de derechos de autor en relación a su Producto Interno Bruto (PIB). Tal como puede verse en la Gráfica 4, la región está en segundo lugar en el mundo a la par que Canadá y Estados Unidos, con un 0,012\% de recaudación sobre el PIB para 2018. El primer lugar lo ocupa Europa, con el 0,028\%, lo que eleva el promedio mundial a $0,0141 \%$ del PIB. Esto lleva a pensar que el modelo actual de negociación de licencias (y de notificación y bajada) ha funcionado instrumentalmente para 
crecer y remunerar a los creadores hasta el momento.

Es cierto que hay desafíos. Los UUC crean fricciones ya que resultan muy difíciles de clasificar en cuanto a su monetización por la publicidad digital, por su diversidad, por el uso circunstancial o sustancial de otras obras sujetas a derechos, y los problemas para trazar una frontera clara entre creadores y consumidores. El principio que prima para todos estos participantes es el de la "desintermediación", y la "innovación" y exploración continuas, algo que justamente choca de frente con los modelos existentes de gestión colectiva, y los vuelve universos complejos para recaudar derechos.

El crecimiento del consumo online está obligando a las SGC de autores a transformar su medición, a flexibilizarse para entender nuevos patrones y a desarrollar nuevos tipos de licencias, teniendo en cuenta las necesidades específicas de cada proveedor de servicios digitales, por ejemplo, Spotify, Apple Music, Netflix, Hulu, Facebook y Google. En este nuevo entorno digital, la gestión de datos se ha convertido en una cuestión prioritaria para las sociedades que ahora deben tratar millones de microtransacciones. Tal como hemos señalado anteriormente, las SGC tienen evidentes deficiencias en cuanto al manejo de su información, ya que se destacan por la falta de datos y transparencia en la distribución de las remuneraciones, lo que constituye sin duda la primera dificultad para saber a quiénes y cómo se paga, y si eso representa una "remuneración justa". En sintonía, existe un llamamiento a contar con mayores estadísticas que permitan entender las estructuras de costos, administración e ingreso para entender los efectos sobre la equidad, los beneficios privados y sociales y, por sobre todo, si un aumento de los ingresos de las SGC o empresas periodísticas va a resultar en una mejor compensación a los autores, creadores originales y trabajadores de prensa.

Los servicios digitales proporcionan nuevas vías para desarrollar oportunidades y modelos de negocios alternativos que respondan y se adapten a los comportamientos actuales de los usuarios y consumidores. Lo que suele estar en juego en los procesos de cambio es el traslado de renta de los sectores tradicionales y sus modelos de negocios por sobre lo disruptivo que atenta con derribar las barreras de entrada que enfrentan nuevos artistas, periodistas, y creadores en general. Esto es sin duda el eje clave de la discusión, y difícilmente pueda sostenerse que se trate en la práctica de remunerar justamente a los creadores.

De hecho, ya existen pagos a creadores por licencias de contenidos para su uso dentro de varias plataformas y servicios, aunque estos responden a acuerdos comerciales entre las partes por conveniencia mutua más que a una obligación regulatoria. Por ejemplo, durante 2019 YouTube pagó más de 3.000 millones de dólares a la industria de la música en concepto de ingresos por publicidad y suscripciones, según informó su CEO Susan Wojcicki, ${ }^{[28]}$ y Facebook, por su parte, ha llegado a acuerdos de licencias con algunas discográficas internacionales como Sony, Universal o Warner, que manejan los derechos de artistas populares en América Latina. La inclusión de regulaciones y obligaciones a este tipo 
de acuerdos y la implantación de medidas restrictivas ex ante para evitar la circulación de contenidos subidos por los usuarios de las plataformas imponen definitivamente un límite a la libertad de expresión, la libertad comercial, y van a resultar contraproducentes para la innovación y la aparición de nuevos creadores de contenidos.

El modelo digital que prima a la hora de consumir obras creativas es el de suscripción más que el de pago único, lo que muestra que el patrón de consumo ha variado. A fines de 2019 había en la región 42 millones de suscriptores a servicios de video on demand vía streaming, y la consultora Digital TV Research anticipa que la cifra casi se duplicará para 2025. ${ }^{[29]}$ Por su parte, Spotify señaló en su último anuncio de resultados financieros que América Latina es una de las regiones con el crecimiento más veloz en suscripciones. ${ }^{[30]}$ Los servicios de streaming tanto de audio como de video constituyen un modelo de negocio que se adapta a la forma de consumo de contenidos en línea. ${ }^{[31]}$ Sin embargo, a pesar del crecimiento y a los acuerdos que las SGC regionales han firmado, por ejemplo, a través de la ventanilla única de sociedades de 15 países según LatinAutor, muchas de ellas insisten en que no hay una remuneración justa (Botero et al 2015).

El cobro a los servicios online por la circulación de publicaciones compartidas por sus usuarios no necesariamente redundará en remuneraciones mayores para los autores, creadores y trabajadores de prensa que generan contenidos. Las regalías en todo caso llegarán a las SGC, cuyo reparto enfrenta cuestionamientos por falta de transparencia, o a las compañías titulares o empleadoras de los creadores, como los editores en el caso de los periodistas. La posibilidad de exigir un pago por parte de intermediarios de Internet no modifica las relaciones contractuales internas, por lo que no necesariamente puede tener correlación con percibir mayores salarios. Este fue un punto criticado por organizaciones gremiales del sector periodístico en Europa, como la Federación Internacional y la Federación Europea de Periodistas (IFJ/EFJ). En síntesis, es muy difícil poder garantizar que alguna medida que regule los pagos y modelos de negocios de los medios necesariamente genere cambios en la retribución de los creadores y periodistas.

\section{La disponibilidad de información de calidad y los límites a la libertad de expresión}

La disponibilidad de información fiable fue uno de los argumentos de la Unión Europea al respaldar el cobro a los servicios online por el uso de parte del contenido periodístico. Producir contenidos implica costos para los medios, ya sea en tiempo o en recursos, y los editores de prensa consideran necesarios pagos de las plataformas para recuperar sus inversiones. Este tipo de reclamos no es nuevo, ya que el periodismo en la región suele estar marcado por cuestiones laborales y salariales en un sector que desde hace varios años se considera en crisis, tal como lo expresa la SIP. Sin embargo, y más allá de la situación de los medios de noticias, no pareciera haber ningún tipo de evidencia empírica que compruebe hoy una clara ausencia de contenidos confiables.

No caben dudas de que la producción de información confiable es positiva para la sociedad. No obstante, existen muchos medios que la generan más allá de las empresas tradicionales. 
Los nuevos medios "nativos digitales" ofrecen propuestas alternativas de monetización con periodismo de muy alta calidad, como por ejemplo Jota o Nexo Jornal en Brasil, Anfibia o Red/Acción en Argentina, CIPER en Chile, Nómada en Guatemala, El Faro en El Salvador, Animal Político en México, La Silla Vacía en Colombia, o IDL reporteros en Perú por citar algunos. ${ }^{[32]}$

Un estudio de Sembramedia de 2017 sobre 100 medios digitales latinoamericanos de Argentina, Brasil, Colombia y México muestra que el nuevo periodismo está bastante ligado a la cultura de creación de nuevas empresas: es básicamente "nativo digital" y tiene alta asociación con causas sociales. En lo que hace al financiamiento, se observa que varios se han abocado a monetizar sus creaciones por las visitas que reciben desde o dentro de los sitios de servicios online. Según dicho estudio, "más del 70\% comenzó con menos de US\$10.000 y más del 10\% de estos hoy está generando más de un millón de dólares anuales en ingresos", a través de más de 15 fuentes distintas de ingresos que incluyen membresía, crowdfunding y publicidad nativa.

Los medios tradicionales de América Latina no están exentos de problemas que afectan la calidad del producto final, más allá de su tamaño. Profesionales de medios convencionales de la región señalaron que "las rutinas periodísticas asociadas a la importancia de la inmediatez y las deficientes condiciones de trabajo y salariales son un freno fundamental en el desarrollo de un periodismo de calidad"[33]. Difícilmente pueda pensarse que la importancia de "la inmediatez", en tanto un fenómeno motivado por la conectividad a Internet ubicua y multiplataforma, cambie por la imposición de derechos de autor sobre buscadores, agregadores de noticias o redes sociales. Además, regular la producción de "periodismo confiable" envuelve el problema de quién establece el criterio de calidad, o el riesgo de fomentar publicaciones alejadas del objetivo básico de informar. La sociedad civil latinoamericana ha venido alertando tanto del peligro que conlleva la censura estatal ${ }^{[34]}$ como la censura privada ${ }^{[35]}$.

Otro riesgo que podría devenir del endurecimiento del derecho de autor es la creación de una oferta de contenidos y noticias dual, asimétrica y de calidades variadas. Por un lado, estarían los medios tradicionales que creen su "jardín vallado" de acceso a contenidos, con poca o nula información disponible en un buscador o agregador y la necesidad de pagar para acceder. ${ }^{[36]}$ Según datos de 2019, las personas que pagan por el acceso digital de noticias no supera el $22 \%$ en Brasil y cae hasta el 7\% en Chile, con toda la región latinoamericana mostrando un promedio del $13 \%$ en línea con la situación mundial. ${ }^{[37]}$ Por otro lado, quedarían los medios que ofrezcan noticias y contenidos similares sin costo directo para el navegante y quizás menor calidad más allá de propuestas puntuales. La preferencia inicial de los lectores muy probablemente sea acceder a las opciones sin costo. Esto reforzaría el tráfico y la popularidad de esos medios y publicaciones, relegando más a los medios tradicionales quienes, al perder tráfico, perderían lectores y, por ende, posibles opciones de monetización para la producción de calidad. En suma, bajo un escenario de acceso y pago de derechos dual, los sectores emergentes y nativos digitales estarían en 
condiciones de tener mayor remuneración con el tiempo y, de ese modo, producir más contenidos que eventualmente ganen en calidad. ${ }^{[38]}$

Además, la necesidad de monitorear que el contenido que circula no incumple normas de derechos de autor y la priorización del derecho de propiedad intelectual por sobre el derecho fundamental a la libre expresión, puede generar incompatibilidades con normas superiores establecidas a nivel constitucional en los países latinoamericanos y el Sistema Interamericano Derechos Humanos (en particular, con el artículo 13 sobre censura previa de la Convención Americana sobre Derechos Humanos) ${ }^{[39]}$. La cantidad de material online es imposible de controlar ex ante: solo en 2013, en Facebook se subían 250 millones de imágenes por día ${ }^{[40]} \mathrm{y}$ en Twitter en 2018 se publicaron 500 millones de tuits diarios ${ }^{[41]}$.

Al invertir la carga de la prueba y volver responsables a los servicios online por lo que compartan sus usuarios, salvo que demuestren haber hecho todo lo posible por evitarlo ("best effort"), se los obliga a usar mecanismos de filtrado automatizado por algoritmos. Como se ha comentado antes, existen varias críticas a la detección automática de infracciones de lo que puede ser contenido inapropiado y a la posibilidad de evitar problemas por medio de excepciones, como estipuló, por ejemplo, la norma europea. No es claro que la tecnología permita diferenciar fielmente los casos exceptuados, y ya hay ejemplos de errores que derivaron en el bloqueo y censura de contenidos lícitos. ${ }^{[42]}$

\subsection{Crecimiento y predominancia de las plataformas}

La nueva economía de datos y de conectividad cuasi ubicua ha cambiado muchos modelos de negocio y obligado a repensar los marcos normativos de impuestos y de competencia, incluidos los análisis y definiciones de mercados relevantes y qué puede constituir dominancia o comportamiento anticompetitivo. Los servicios en línea son actores que vienen cobrando relevancia en los últimos años y sobre los cuales todavía no existe un consenso regulatorio, con discusiones abiertas en los países desarrollados para ver cómo deben encuadrarse en su legislación. Las grandes casas editoras de prensa suelen argumentar su pelea contra las plataformas por la dominancia de estas últimas en la captación de renta publicitaria. Sin embargo, es difícil atribuir que esa captación se dé precisamente por sus contenidos per se o más bien por el valor agregado de indexación y relevancia a cada usuario que estas prestan.

La propia lógica de Internet tiende a que predominen efectos o externalidades de red: mientras mayor es el número de usuarios, mayor valor o utilidad tiene un bien o servicio. Los servicios online se presentan como un mercado de varios lados, que funciona al unir oferentes y consumidores y donde se pueden producir efectos de red directos (un incremento en el uso del bien genera un incremento en su valor) e indirectos ( el uso de un producto o servicio impulsa la producción y valor de otros complementarios, lo que a su vez aumenta el valor del producto original). Un intermediario o plataforma es necesario para internalizar las externalidades de red indirectas creadas por un grupo de usuarios en el otro grupo de usuarios. 
Las plataformas fijan las condiciones de acceso en cada uno de los lados del mercado de tal manera que induzca a los diferentes grupos de usuarios a unirse:

- Las plataformas comerciales suelen ser mercados de dos o más lados transaccionales que reúnen potenciales vendedores y compradores, con el objetivo de que entre ellos realicen una o varias transacciones directas a través de la plataforma.

- Las plataformas de publicidad son consideradas mercados de dos o más lados no transaccionales, ya que sobre ellas no se da una transacción directa, sino que reciben publicidad de los anunciantes que pagan por acceder a sus usuarios.

Este tipo de economía de red concentra usuarios y auspiciantes en servicios populares, porque ambos tienen beneficios de estar donde está presente la mayoría de los usuarios. Algunos académicos como el profesor de University College London David S. Evans (2013) sostienen que los exámenes sobre dominancia y comportamiento anticompetitivo deberían observar la competencia por captar y retener la atención de las personas, más allá del mercado tradicional o tipo de producto o servicio que una compañía provea. Bajo esta perspectiva, los servicios en línea compiten entre sí y contra todos por el tiempo de ocio de las personas, que es finito.

Tal como señala la OCDE (2018), existen numerosos desafíos sobre la forma correcta de medir la dominancia de las plataformas o mercados de múltiples lados que operan globalmente, por lo que es necesario repensar las herramientas tradicionales para esta función. ${ }^{[43]}$ En América Latina, la agenda regulatoria sobre las plataformas digitales se ha centrado en cuestiones impositivas con mirada retrospectiva pero no tanto hacia adelante sobre competencia. Hasta el momento, el foco ha estado puesto en temas como el cobro de Impuesto al Valor Agregado (IVA) recomendado por la Comisión Económica para América Latina y el Caribe (CEPAL) ${ }^{[44]} \mathrm{y}$ en la licitud de la retirada de contenidos, o en la fijación de controles sobre campañas de desinformación (noticias falsas) y discursos de odio. Este último aspecto ha recibido alta atención mediática y ha sido materia de debates legislativos durante la pandemia ante la (no) retirada de contenidos de redes sociales de altas personalidades políticas regionales.

En el mundo desarrollado se han llevado adelante distintos casos de concentración sobre las plataformas conocidas como Big Tech (entre las que se incluye a Google, Amazon, Facebook, Apple y Microsoft) por el Departamento de Justicia y la Comisión Federal de Comercio de los Estados Unidos, así como también de la Comisión Europea. Quizás el más relevante para este abordaje sea el estudio recientemente publicado sobre el mercado de publicidad digital y las plataformas online llevado adelante por la Autoridad de Mercados y Competencia (CMA por sus siglas in inglés) del Reino Unido ${ }^{[45]}$. En este reporte se ha encontrado que Google y Facebook poseen ventajas de posicionamiento estratégico que tienen efectos inhibitorios para la entrada y expansión de competidores. El reporte consideró que estos efectos pueden afectar a los consumidores y a la innovación, y recomendó crear una unidad especial (DMU por sus siglas en inglés), que sea empoderada 
para promover medidas pro-competitivas ex-ante. Entre las medidas mencionadas se destaca la creación de un código de conducta para gobernar las plataformas financiadas por publicidad digital que posean un status de mercado estratégico que el DMU debe actualizar y mantener. También se recomendó que le sea otorgado al DMU el poder de acceder a los datos e intervenir respecto de su manipulación y uso en la cadena de valor, con la facultad de separarlos, exigir control de los consumidores y promover la interoperabilidad (CMA 2020). Resta verse como serán efectivamente implementadas estas medidas.

De cualquier manera, está claro que las plataformas de internet han generado un nuevo mercado a partir del conocimiento del usuario y del manejo de sus datos, hecho que ha producido numerosas externalidades positivas, favoreciendo la agregación de oferta y demanda y estimulado nuevas cadenas de valor. Es cierto que su crecimiento y predominancia trae riesgos de concentración, que hay que atender y estudiar. Sin embargo, esto debe hacerse con sumo cuidado, ya que en los mercados de múltiples lados las distintas partes no necesariamente representan el todo por el cual obtienen sus ingresos ${ }^{[46]}$. Aquí, lo más difícil de definir son los mercados relevantes y hasta qué punto un determinado comportamiento representa un abuso de posición dominante, por ejemplo, en el mercado publicitario o de los contenidos en línea, cuando el activo principal son el conocimiento y los datos de los visitantes y no tanto una referencia o vínculo per se. Por todo esto, es fundamental contar con un enfoque "multicomprensivo" para entender sus alcances y las transformaciones corrientes (Becerra y Mastrini 2019), las cuales deben estar basadas en datos empíricos, el nivel de sustitución y complementariedad del uso de los datos con sus respectivas relaciones de causalidad.

Como hemos visto, el mercado de la publicidad es muy dinámico y se va desplazando hacia aquello que atraiga la atención de sus prospectivos clientes. No solo está sujeto a patrones tecnológicos y de mercado sino también culturales y generacionales. Al crecer hacia lo digital -aún más tras la pandemia-, es de esperarse que promueva efectos de red que tiendan a generar concentraciones de mercado. Sin embargo, la dominancia y la existencia de conductas anticompetitivas deben estudiarse precisamente en cada mercado nacional y las medidas a tomarse deberían estar destinadas a promover la competencia, pensando en estimular los ecosistemas regionales. En cualquier caso, nada indica que este tipo de intervenciones se deban llevar a cabo mediante imposiciones sobre el derecho de autor (tal como se aplicaba en el mundo analógico), forzando a una transferencia de rentas (mediante licencias o derechos obligatorios) de un sector creciente a otro sin entender si esto va a favorecer el ambiente competitivo y la aproximación al óptimo social analizado en la sección anterior. La visión debería estar puesta en favorecer al consumidor o usuario de bienes y servicios digitales, no en promover subsidios cruzados ya que esto podría resultar aún más distorsivo y perjudicial a promover una dinámica local innovadora que estimule la aparición de nuevos modelos de negocio de empresas editoriales, creadoras de contenidos y obras que se ajusten a las nuevas generaciones.

\subsection{Impacto en la innovación y producción de contenidos}


Tal como hemos visto en el abordaje teórico de la Sección 3, existe la idea proveniente de la propiedad intelectual de que trasladar mayor control sobre los derechos de autor al medio digital resultará en un aumento de la producción, creatividad e innovación. El análisis de un argumento como este debe tener en cuenta la realidad del sector creativo en cada contexto. En particular en el mundo en desarrollo, donde el medio digital ha permitido bajar las barreras a la producción, el acceso a mercados y la facilitación del consumo, haciendo crecer los mercados de las noticias, la música, el arte, y la producción audiovisual, entre otros, aunque hayan cambiado los formatos. Además, en América Latina muchos de los contenidos que se consumen aquí tienen su origen y titularidad en otras latitudes. Por ejemplo, de acuerdo con un reporte de 2016 elaborado por GSMA ${ }^{[47]}$, "sólo cerca del 30\% del tráfico de internet en América Latina se dirige a sitios alojados localmente y en idioma local". Esto sería un indicador de que regulaciones más estrictas en temas de derechos de autor no tendrían un impacto económico tan relevante para la región sino más bien en otras regiones.

Medidas que aumenten la protección y pagos por derechos de autor en América Latina, con la directiva europea como modelo, generarían una transferencia de recursos mayor hacia afuera de la región, donde están la mayoría de sus tenedores de derechos. En este caso, el flujo de divisas transatlántico de la propiedad intelectual -de la que el derecho de autor es parte- aumentaría aún más a la vista, por ejemplo, en la Gráfica 4 de CISAC, ya que, además de los ingresos a los productores locales, los tenedores de derechos del resto del mundo tendrían otro vehículo de cobro a los usuarios dentro de los países que lo lleven adelante. Tal como puede verse en la Tabla 2 a continuación, la balanza de pagos de la propiedad intelectual ya es de por sí bastante deficitaria para toda la región: la diferencia de pagos y recibos es de 8,1 veces y totaliza US\$9.974 millones.

\section{Tabla 2: La "Des-balanza" de pagos en propiedad intelectual en América Latina}

Cargos por el uso de propiedad intelectual (balanza de pagos en US\$ a precios actuales) ${ }^{[48]}$ 


\begin{tabular}{|c|c|c|c|c|c|c|}
\hline Países & \multicolumn{2}{|c|}{ Pagos en 2018} & \multicolumn{2}{|c|}{ Recibos en 2018} & \multirow{2}{*}{$\begin{array}{l}\text { Déficit } \\
\$(1.756 .913 .030)\end{array}$} & \multirow{2}{*}{$\begin{array}{l}\text { Diferencia } \\
7,5 \mathrm{x}\end{array}$} \\
\hline Argentina & $\$$ & 2.025 .250 .465 & $\$$ & 268.337 .435 & & \\
\hline Bolivia & $\$$ & 83.331 .793 & $\$$ & 26.264 .446 & $\$ \quad(57.067 .347)$ & $3,2 \mathrm{x}$ \\
\hline Brasil & $\$$ & 4.923 .834 .063 & $\$$ & 825.475 .487 & $\$(4.098 .358 .576)$ & $6,0 \mathrm{x}$ \\
\hline Chile & $\$$ & 1.783 .075 .197 & $\$$ & 46.185 .212 & \$ (1.736.889.985) & $38,6 x$ \\
\hline Colombia & $\$$ & 470.336 .097 & $\$$ & 104.817 .445 & $\$ \quad(365.518 .651)$ & $4,5 \mathrm{x}$ \\
\hline Costa Rica & $\$$ & 565.152 .000 & $\$$ & 5.921 .462 & $\$ \quad(559.230 .538)$ & $95.4 \mathrm{x}$ \\
\hline El Salvador & $\$$ & 98.780 .318 & $\$$ & 23.049 .634 & $\$ \quad(75.730 .684)$ & $4,3 \mathrm{x}$ \\
\hline México & $\$$ & 301.983 .326 & $\$$ & 6.997 .263 & $\$ \quad(294.986 .063)$ & $43,2 x$ \\
\hline Panamá & $\$$ & 39.400 .000 & $\$$ & 21.700 .000 & $\$ \quad(17.700 .000)$ & $1,8 x$ \\
\hline Perú & $\$$ & 349.222 .679 & $\$$ & 25.873 .714 & $\$ \quad(323.348 .965)$ & $13,5 x$ \\
\hline Uruguay & $\$$ & 117.351 .002 & $\$$ & 33.609 .178 & $\$ \quad(83.741 .823)$ & $3,5 x$ \\
\hline $\begin{array}{l}\text { A. Latina y } \\
\text { el Caribe }\end{array}$ & $\$$ & 11.374.060.744 & $\$$ & 1.399.707.066 & \$ (9.974.353.679) & $8,1 x$ \\
\hline
\end{tabular}

Fuente: Fondo Monetario Internacional (IMF Data 2019).

La implementación de medidas como la europea, que invierten las responsabilidades del control y obligan a firmar licencias con todos los productores de contenidos junto con la implementación de filtros, podrían afectar principalmente a las nuevas empresas de Internet locales que busquen indexar o agregar contenidos. Además, es posible que los emprendimientos de intermediación de menor escala difícilmente cuenten con fondos, tiempo o conocimiento para desarrollar sistemas propios de detección de infracciones o negociación de licencias, tal como posee YouTube con su sofisticado sistema de "Content ID", el cual identifica de manera automática si un contenido protegido por derechos de autor (música, videojuegos, películas, etc.) ha sido utilizado por otra persona en sus vídeos. ${ }^{[49]}$ Los costos asociados a tener este tipo de servicios pueden volver no sustentables 
en lo inmediato o en el corto plazo a dichos emprendimientos (y, por tanto, tornarse en una medida anticompetitiva). Las compañías de mayor escala nacional o regional son de todas formas menores que las plataformas globales y verán probablemente afectados sus ingresos e inversiones.

Además, los procesos de denuncia y resolución de diferencias por derechos de autor van a incrementarse cualquiera sea la escala de la plataforma, generando mayor burocracia, costos administrativos y legales para las firmas e incluso para los usuarios. Nuevas empresas digitales se crean en América Latina cada año, este es un sector con enormes necesidades de financiamiento que a su vez enfrentan obstáculos en la carga impositiva y las regulaciones sobre cumplimiento normativo (compliance), aspectos que una norma como la europea definitivamente empeoraría ${ }^{[50]}$. De este modo, es claro que el cambio de las condiciones de "puerto seguro" resultaría en la creación de una barrera a la entrada, reduciría la innovación y la consecuente posibilidad de tener mayor competencia. Todo esto, por supuesto, resultaría en una situación de menor bienestar en los términos definidos en la Sección 3.

La creación de contenido y subida a las plataformas tradicionales, que facilitaban el inicio de nuevos servicios, seguramente podría verse limitada. Ejemplos de sectores afectados pueden ser el de eSports o streamers de videojuegos que gozan de creciente popularidad vía plataformas como Twitch o YouTube Gaming, donde la modalidad conocida como "Let's play" consiste en filmar a alguien jugando y comentando sobre un juego por el cual otras compañías poseen derechos. Aquí habría una infracción a la ley en tanto implica una reproducción (en muchos casos íntegra) de los contenidos de una obra. Sin embargo, es mayormente tolerada por las prácticas de la industria de los videojuegos. Tal como señala Mantegna (2017), "esta contradicción coloca a los streamers en una situación de precariedad, donde su actividad reposa en una zona gris legal (bastante oscuro) y en la voluntad de los titulares de los derechos autorales de no perseguir las infracciones" ${ }^{\text {[51] }}$. En este sector existen varias empresas regionales que atraen talento y generan ingresos considerables, y que están actuando en el mercado global. Se estima que América Latina y el Caribe posee 397 millones de jugadores y es la segunda región con mayor incremento en la industria de los videojuegos, con un crecimiento anual del 13,5\%, guiado tanto por la producción de juegos como por la organización de competencias a su alrededor. ${ }^{[52]}$

El control de la copia no autorizada o la piratería es una materia debidamente abordada en la legislación que debe reforzarse. Sin embargo, muy distinta es la búsqueda de mayores mecanismos de compensación y control sobre el derecho de autor, las cuales serán muy probablemente contraproducentes para el mismo sector de la creación, ya que aumentarían los costos y de este modo desincentivarían la búsqueda de nuevos formatos o el uso parcial de material para motivar nuevas producciones. En el marco de funcionamiento actual de las SGC, las cuales cuentan con amplia libertad para definir tarifas, los sujetos y las modalidades obligadas a pagar, y donde además, sus formas de distribución del recaudo y sistemas de gobernanza son materia de discusión en la propia industria (Botero et. al 2015), 
empoderarlas sería prácticamente poner un freno a toda actividad de innovación y creación local. Incluso, ya se ha demostrado que el comportamiento de las SGC resulta a veces anticompetitivo por abuso de posición dominante. Por ejemplo, la Secretaría de Comercio de Argentina, a instancias de una investigación realizada por la Comisión Nacional de Defensa de la Competencia (CNDC), multó a la Sociedad Argentina de Autores y Compositores de Música (SADAIC) por $\$ 42,7$ millones de pesos argentinos por precios excesivos en los aranceles de derechos de autor de entre seis y nueve veces más que otros países de referencia que pagan los hoteles y otros establecimientos que ofrecen alojamiento. ${ }^{[53]}$

Se ha visto que los mismos artistas han llegado a verse impedidos de hacer los llamados "vivos" en redes sociales ante la exigencia de SGC que les reclaman un recaudo que, de acuerdo con sus propias reglas de distribución, nunca volverían a sus propias manos. Durante los aislamientos obligatorios ocasionados por la pandemia de la COVID-19, empresas de eventos virtuales a través de las redes sociales, fueron notificados por las SGC para abonar derechos que en varios casos excedían los resultados de los asistentes de las transmisiones o su propio recaudo, lo que hizo que fueran canceladas. Así las cosas, incluso el productor cinematográfico Axel Kuschevatzky criticó que fuera "más barato poner una canción en inglés en una película británica que en una película argentina", lo que motiva a que los realizadores argentinos reduzcan la presencia de música nacional en sus trabajos. ${ }^{[54]}$

Finalmente, es importante considerar que medidas del tipo europeo aplicadas en algunos países de la región podrían acarrear mayores costos de transacción o administrativos (como fueron definidos en la Tabla 1) para los servicios online originados en estas geografías, creando una Internet asimétrica entre los exceptuados y aquellos alcanzados bajo la regulación, y con distorsiones e incentivos a localizar los contenidos en los países más favorables. Los intentos regulatorios nacionales, con sus posibles diferencias, podrían a empeorar la ya de por sí disímil regulación de Internet en la región, a contramano de las recomendaciones de organismos regionales tales como la CEPAL el Banco de Desarrollo de América Latina (CAF) o el Banco Interamericano de Desarrollo (BID), que destacan la necesidad de buscar mayor convergencia de políticas para lograr constituir un "Mercado Único Digital", con una Internet más armonizada que permita hacer negocios con escala regional. El riesgo de la fragmentación regulatoria es evidente.

Existe toda una "nueva economía" cuyos vectores de desarrollo todavía se desconocen y que funcionan con lógicas muy distintas a las del sector tradicional de contenidos o de las SGC que esperan un retorno por cada reproducción musical, lectura o uso de su creación. Una pregunta relevante para hacerse y analizar, pero que está por fuera de este trabajo, es si América Latina debería privilegiar a sectores tradicionales a un punto tal que los costos de su protección y promoción excedan las desventajas de contar con nuevas barreras a la entrada de otro sector de creadores y agregadores de la nueva economía y, a su vez, de mayores costos de transacción y consumo para los consumidores. 


\section{Conclusiones}

El análisis anterior nos lleva a pensar que América Latina, en tanto región en desarrollo con insuficiencias de estímulo a la creación de contenido local y la presencia de significativas barreras regulatorias e impositivas, se va a ver más beneficiada de un régimen más abierto a la difusión de contenidos, conocimientos y a la innovación, aprovechando la ubicuidad de Internet, que de uno cerrado. Esto se apoya en algunas de las lecciones aprendidas de la teoría de la propiedad intelectual sobre la difusión del conocimiento y la innovación que señalan que "sin imitación no es posible innovar" (Cimoli, Dosi y Stiglitz, 2009) y que el desarrollo de las economías emergentes está asociado a la imitación creativa y la absorción (Archibugi y Filippetti, 2010).

Las preocupaciones por la piratería son legítimas y están abordadas hoy en las legislaciones nacionales. Requieren de una vigilancia mayor pero no necesariamente de una nueva regulación, y deberían separarse de la discusión de las reformas más amplias al derecho de autor. En este trabajo se argumenta que aumentar el control del derecho de autor para asegurar que las creaciones originales reciban una remuneración "que justifique" sus inversiones no debería ser principal motivador de reformas en regiones como América Latina, sino las de considerar una mejor adecuación de legislaciones antiguas y restrictivas al nuevo entorno digital regional, a fin de hacerlo más interoperable y así promover mayores producciones, nuevos sectores de desarrollo y consumo en línea de acuerdo a los nuevos patrones de uso. Propuestas que vayan en el sentido europeo, que incluyan desplazar vía regulación la carga del control a los intermediarios de Internet, promover el filtrado ex ante $\mathrm{y}$, en particular, obligar a desarrollar mecanismos de remuneración a favor de actores tradicionales (medios editoriales y SGC), puede ser altamente perjudicial, en particular para el mundo en desarrollo. En base a estos supuestos podríamos decir que el óptimo social del control en mercados más imperfectos, con mayores trabas intrínsecas y brechas, seguramente se ubique en un nivel de control más inferior que el mundo desarrollado. En este sentido van también las recomendaciones de autoridades en teoría del derecho de autor como Landes y Posner (1989) quienes señalan que, para promover las creaciones, será preferible limitar la protección a un nivel menor al que maximice las ganancias de los autores y creadores.

En la nueva economía de datos caracterizada por la creciente masificación de Internet, se ha democratizado el acceso a la información y se ha estimulado singularmente la participación de los usuarios en la creación de sus propias obras, derivadas y originales, ofreciéndoles también canales muy accesibles para ampliar su difusión. Es así como aparecieron nuevas "especies" como los gamers, YouTubers, los influencers y otros nuevos artistas y medios digitales, estimulando un círculo virtuoso de innovación y nuevas oportunidades comerciales, creativas y productivas. A pesar de esto, la Unión Europea ha llevado adelante una reforma singular que refleja de alguna manera un triunfo de sectores tradicionales, tenedores de derechos de autor, que han forzado a nuevos sectores a 
ajustarse a sus modelos de negocio y marcos normativos legados. Ante esta realidad, es menester prestar atención a los consumidores y al tipo de ambiente de Internet en que estos pueden desarrollarse a raíz de medidas de mayor protección al derecho de autor. Los cinco aspectos abordados en la Sección 4 resultan críticos para poder repensar apropiadamente nuevas reformas teniendo en cuenta las dinámicas introducidas a través del entorno digital latinoamericano.

La forma en que se producen, comparten y consumen contenidos ha venido cambiando constantemente en Internet en tanto ha crecido su proliferación. Sin embargo, todavía un $44 \%$ de los latinoamericanos no acceden a Internet, en muchos casos porque no pueden pagarla, en otros porque no existe contenido local relevante o faltan habilidades para su uso $\mathrm{y}$, finalmente, en otros casos más marginales que afectan al 7\% de la población, por falta de cobertura de los servicios. ${ }^{[55]}$

Muy probablemente, por estas cuestiones, esta región tenga un óptimo social de control del derecho de autor diferente al del viejo continente. Por estos lados, el acceso y la difusión de Internet y sus contenidos es lo que debería primar por sobre cualquier otra medida regulatoria. Sin acceso no hay posibilidades de consumo ni de creación. Tal como se ha visto en la Sección 4.3, el sector de los contenidos sujetos a derechos de autor pesa relativamente menos al europeo, 0,012\% del PIB regional, y es mucho menor a la economía digital. Por lo tanto, es difícil pensar que los beneficios de aumentar la protección del derecho de autor per se puedan superar también los costos y las asimetrías que se generen y si, en suma, estas pudiesen producir una mejora del bienestar tal como fuera conceptualizado en la Gráfica 1.

La falta de estudios empíricos sobre cómo se comportan la oferta y demanda de la industria de bienes sujetos a derechos de autor en el mundo desarrollado hace pensar que hay que actuar con más cautela todavía en los países en desarrollo, donde el tamaño de las industrias creativas es todavía menor y hay mayores barreras a la entrada (de ingresos, recursos disponibles, incentivos, fiscalidad, etc.). Mayor transparencia tanto por parte de las plataformas como por parte de las SGC puede ayudar a entender las dinámicas específicas del derecho de autor en el entorno digital. Esta es una condición indispensable para promover reformas en estas materias, que deberían tener una mirada más integral, ser analizadas de manera multidisciplinaria y ajustadas a un plan de desarrollo de los ecosistemas regionales y locales de Internet. Más allá de esto, tal como se ha ensayado a lo largo del trabajo, privilegiar a los pocos actores establecidos puede ser contraproducente para estimular el desarrollo de una industria más abierta, enfocada en la innovación, que promueva el surgimiento de nuevos medios digitales y nuevas creaciones artísticas ajustadas al medio en el que se desenvuelven. Solo de este modo, podrá haber una mayor demanda y consumo de obras locales que supere el déficit de contenido local persistente en nuestra región y, a su vez, estimule aún más la oferta. 


\section{Referencias Bibliográficas}

Archibugi, Daniele, and Andrea Filippetti. 2010. "The Globalisation of Intellectual Property Rights: Four Learned Lessons and Four Theses." Global Policy 1, no. 2 : 137-49. https://doi.org/10.1111/j.1758-5899.2010.00019.x.

Arthur D. Little. 2017. "The Calm Before The Storm. ADL Media Flow of Funds". January 2018 y "Consolidate. Diversify and Perish. ADL Media Flow of Funds". Becerra, M. y Mastrini G.2019 La convergencia de medios, telecomunicaciones e internet en la perspectiva de la competencia: Hacia un enfoque multicomprensivo. UNESCO.

Boczkowski, Pablo, Eugenia Mitchelstein, y Mora Matassi. 2017. "Incidental News: How Young People Consume News on Social Media." Proceedings of the 50th Hawaii International Conference on System Sciences, https://doi.org/10.24251/hicss.2017.217.

Botero C., Guzmán L. y Cabrera K. 2015. "La gestión colectiva ante el desafío digital en América Latina y el Caribe”, IDRC y Fundación Karisma.

Bradford, Anu. 2012. «The Brussels Effect». Northwestern University Law Review 107 (1), Columbia Law and Economics Working Paper No. 533.

Ceurvels, M. 2019. "Digital Ad Spending Latin America 2019”, eMarketer.

Cimoli, Mario, Giovanni Dosi, y Joseph E. Stiglitz. 2009. "The Future of Industrial Policies in the New Millennium: Toward a Knowledge-Centered Development Agenda." Industrial Policy and Development, 541-60.

https://doi.org/10.1093/acprof:oso/9780199235261.003.0020.

CISAC, Informe Anual 2019 e Informe de Recaudaciones 2018, editado en 2019.

Deloitte. 2019. "The impact of web traffic on revenues of traditional newspaper publishers" A study for France. Germany. Spain and the UK. Prepared for Google.

Elkin-Koren, Niva, Nahmias, Yifat y Perel (Filmar), Maayan. 2019. "Is It Time to Abolish Safe Harbor? When Rhetoric Clouds Policy Goals". Stanford Law \& Policy Review. Forthcoming. Disponible en SSRN: https://ssrn.com/abstract $=3344213$

Evans, David S. 2013. "Attention Rivalry among Online Platforms and Its Implications for Antitrust Analysis." SSRN Electronic Journal. https://doi.org/10.2139/ssrn.2195340.

GAO. 2010. “Intellectual Property: Observations on Efforts to Quantify the Economic Effects of Counterfeit and Pirated Goods". Washington DC: Government Accountability Office.

Handke, Christian. 2010. "The Economics of Copyright and Digitalisation - A Report on the Literature and the Need for Further Research." SSRN Electronic Journal. https://doi.org/10.2139/ssrn.2707153. 
Humphreys, Peter, y Seamus Simpson. 2018. "Regulation, Governance and Convergence in the Media". Northampton. MA: Edward Elgar Publishing.

https://doi.org/10.4337/9781781008997.

IFPI. 2019. "The Global Music Report 2019”, https://www.ifpi.org/resources/

Landes, William M., y Richard A. Posner (1989). "An Economic Analysis of Copyright Law". The Journal of Legal Studies, 1989, 325-363.

Leveque, Francois y Ménière, Yann. 2004. "The Economics of Patents and Copyright". Berkeley Electronic Press. Disponible en SSRN: https://ssrn.com/abstract=642622

Liebowitz, Stan. 2018. "Economic Analysis of Safe Harbor Provisions", estudio encargado por CISAC.

Mantegna, Micaela. 2017. "Let's Play! Streaming, propiedad intelectual y fair use", artículo publicado en GeekyLegal, https://www.geekylegal.com/articulos

Mansell, Robin, y W Edward Steinmueller. 2013. "Copyright Infringement Online: The Case of the Digital Economy Act Judicial Review in the United Kingdom." New Media \& Society 15, no. 8: 1312-28. https://doi.org/10.1177/1461444812470429.

Nadel, Mark S. 2004. "How Current Copyright Law Discourages Creative Output: The Overlooked Impact of Marketing". Berkeley Technology Law Journal, Vol. 19, 785-856. Disponible enSSRN: https://ssrn.com/abstract $=489762$

OCDE. 2015. "Enquiries Into Intellectual Property's Economic Impact" Chapter 5: Copyright in the Digital Era.

OCDE. 2018. "Rethinking Antitrust Tools for Mulit-Sided Platforms.

Reuters Institute (2020, 2019 y 2018): "Digital News Report”. Oxford University. http://www.digitalnewsreport.org

Sembramedia. 2017. Punto de Inflexión. Impacto. Amenazas y Sustentabilidad: Estudio de emprendedores de medios digitales latinoamericanos, http://data.sembramedia.org/wp-content/uploads/2017/09/Punto-de-Inflexion-SembraMediaspan-7-24.pdf

UK's Competition and Market Authority.2020 “Online platforms and digital advertising market study. Final Report", https://www.gov.uk/cma-cases/online-platforms-and-digital-advertising-market-study

Watt, Richard. 2009. "An empirical analysis of economic of copyright: how valid are the results of studies in developed countries for developing countries". WIPO: The Economics of Intellectual Property. Suggestions for Further Research in Developing Countries and Countries in Transition, Geneva. 
Watt, Richard. 2014. "Copyright Collectives: Some Basic Economic Theory." Handbook on the Economics of Copyright,167-78. https://doi.org/10.4337/9781849808538.00019.

Wunsch-Vincent, Sacha. 2016. "The Economics of Copyright and the Internet. Moving to an Empirical Assessment Relevant in the Digital Age". Handbook on the Economics of the Internet.

WIPO “Enforcing Intellectual Property Rights: An Economic Perspective”. Geneva: World Intellectual Property Organization Advisory Committee on Enforcement. Fifth Session. November 2 to 4 prepared by C. Fink.

WIPO. 2016. "Understanding Copyright and Related Rights", Geneva, https://www.wipo.int/publications/en/details.jsp?id=4081

\section{Agradecimientos}

Una versión previa de este trabajo fue publicada por la Universidad de San Andrés de Argentina en diciembre de 2019 en el marco del Programa de Intermediarios de Internet y Economía Digital del Centro de Tecnología y Sociedad. La misma está disponible en: http://hdl.handle.net/10908/16695. El autor agradece el trabajo de investigación y la colaboración de Ariel Riera, así como los valiosos comentarios de Guillermo Cruz. Comentarios: scabello@udesa.edu.ar

\section{Biografía del Autor}

Sebastián M. Cabello: experto en políticas públicas digitales y consultor de distintas entidades del sector público y privado. Actualmente es CEO de SmC+ Digital Public Affairs y asesor del Banco Interamericano de Desarrollo (BID) y la Asociación Latinoamericana de Internet (ALAI) entre otros. También es investigador afiliado del Centro de Tecnología y Sociedad (CETyS) de la Universidad de San Andrés, Argentina. Es Licenciado en Economía de la Universidad Nacional del Sur (UNS) y posee un Máster en Relaciones Internacionales de la Universidad de California, San Diego (UCSD).

\section{Notas}

La aseveración del Digital News Report está basada en el promedio de los países donde se tomaron muestras en abril 2020 -Reino Unido (2191 casos), Alemania (2003 casos), Estados Unidos ( 1221 casos), España (1018 casos), Corea del Sur (1009 casos) y Argentina (1003 casos)- que respondieron a la pregunta "de qué medios se han abastecido de noticias en la última semana". Para mayor detalle véase: https://reutersinstitute.politics.ox.ac.uk/digital-news-report-2020-resumen-ejecutivo-y-hallazgos-clave 
†2 Véase el Diario Oficial de la Unión Europea L 130/92 del 17 de mayo de 2019.

t3 Se trata de ofrecer al proveedor de servicios tecnológicos o plataformas intermediarias un puerto seguro (safe harbor), mecanismo que lo mantiene a salvo de la responsabilidad legal, siempre y cuando cumpla con las obligaciones específicas aplicables.

†4 El debate europeo se centró en la prensa, y excluyó a las publicaciones académicas y los blogs sin editor responsable. También se dejó fuera el acto de 'linkear", la cita de datos puntuales, o el uso de "muy breves extractos", fraseo que en última instancia cada país miembro decidirá cómo entender.

De aquí se exceptúa a los servicios de monitorear o supervisar genéricamente los contenidos. Se excluye de los casos de infracción el uso de citas, o publicaciones que tengan como fin la crítica, parodia o reseña de contenidos protegidos. relacionados con la libertad de expresión. También, se abre la posibilidad de que los países miembros exceptúen sociedades sin fines comerciales o que no generen "ingresos significativos".

t6 Véase declaración del 11 de marzo donde se solicita que la UE debe "alinear su Directiva de Copyright a los estándares internacionales de los derechos humanos"

Véase la posición de la Electronic Frontier Foundation y la carta abierta de 57 organizaciones de la sociedad civil entre muchos otros,

17 https://www.eff.org/deeplinks/2019/02/artists-against-article-13-when-big-tech-and-big-content-make-meal-creators-it y https://www.liberties.eu/en/news/delete-article-thirteen-open-letter/13194

Ver documento del Consorcio "Al Sur" del 23 de abril de 2019: "La Directiva Europea de Derecho de Autor y su impacto en los usuarios de América Latina y el Caribe: una perspectiva 8 desde las organizaciones de la sociedad civil",

https://web.karisma.org.co/la-directiva-europea-de-derecho-de-autor-y-su-impacto-en-los-usuarios-de-america-latina-y-el-caribe-una-perspectiva-desde-las-organizaciones-de-la-sociedad-civil/

19 Véase Asociaciones de prensa iberoamericanas reivindican los derechos de autor en Internet, http://adepa.org.ar/tercera-reunion-de-asociaciones-de-prensa-en-rio-de-janeiro/

†10 Véase Declaración de Salta sobre Principios de Libertad de Expresión en la Era Digital, https://www.sipiapa.org/notas/1212813-sip-aprueba-la-declaracion-salta-la-era-digital

Varias corrientes de pensamiento económico cuestionan que reforzar los derechos de autor sea la mejor manera de proteger la propiedad cultural e intelectual. Aún en el caso extremo de la piratería hay quienes sostienen que en algún grado esta puede ser socialmente deseable, incluso para los tenedores de derechos (Mansell y Steinmueller, 2013).

112 En el mismo sentido Nader (2004) sostenía que los costos de marketing y promoción muchas veces exceden a los de creación y que la sobreprotección de derechos de autor crea barreras de entrada a las nuevas producciones que no pueden invertir en marketing y previene que nuevos modelos de negocio y nuevas creaciones puedan aparecer.

Estos autores incluso sostienen que la eliminación del puerto seguro puede ir en contra de los propios creadores individuales ya que los obliga a intermediar con editoras y productoras musicales en vez de manejarse directamente con las plataformas, y negociar sus propios acuerdos.

A este respecto Botero et. al (2015, pp. 127) señala: "Debe analizarse si las ventajas para las SGC (en relación con eficiencia y precio, por ejemplo) supone desventajas similares en la 14 medida que se estaría formando un monopolio (cartel) que obligaría a todo creador de la región a utilizar el mismo intermediario, disminuyendo considerablemente sus opciones en el mercado, especialmente para los mas pequeños, nuevos y/o independientes."

115 Para expandir en el concepto de "interés público" relativo al derecho de autor véase entrevista a Claudio Ruiz de Creative Commons en Revista Noticias 19 de julio de 2017,

https://noticias.perfil.com/noticias/cultura/2017-07-19-derechos-de-autor-en-internet-un-debate-en-torno-a-la-propiedad-intelectual.phtml

Como puede verse en la gráfica, no se dibuja la curva de Oferta porque su forma precisa puede variar. Al ser una agregación de las curvas de costos marginales de los productores, una

t16 curva de Oferta creciente implica que las curvas de costos marginales de los productores son crecientes, es decir que la producción de estos bienes presenta rendimientos decrecientes a escala, lo cual puede no ser válido para todos los bienes o creaciones sujetos a derechos de autor.

The Guardian, por ejemplo, reportaba en marzo 2020 un 39\% de nuevos suscriptores digitales en su app y versión Tablet respecto de marzo 2019. En tanto The New York Times llegaba a 6 millones de suscriptores digitales a fines de abril 2020, a pesar de eso, sus ingresos de publicidad arrojaban una caída año a año.

†18 Op. Cit. véase también “El medio ya no es el mensaje”. revista Anfibia, http://revistaanfibia.com/ensayo/medio-ya-no-mensaje/

Un estudio econométrico de Deloitte (2019) estimó el impacto del tráfico web en 51 medios de prensa principales con y sin jardín vallado en el Reino Unido, Francia, Alemania y España entre 2015 y 2017, y encontró que el tráfico web fue el responsable del 10,2\% de sus ingresos totales (1.646 millones de euros en 2018). En particular, el tráfico referido representó un $6,2 \%$ del ingreso de los medios (1.015 millones de euros). En estos países, solo el 39\% del tráfico es directo, es decir, se produce por escribir la URL en la barra de direcciones o por acceder a los sitios agendados. El restante $61 \%$ de las visitas era básicamente referido desde buscadores, agregadores de noticias, blogs o redes sociales.

t20 Un muro de pago (en inglés paywall) es un sistema que restringe el acceso a contenido a usuarios que no cuentan con una suscripción pagada (Véase por ejemplo Radoff, “A Brief History of Paywalls", 2009)

†21 Véase Ceurvels, M., “Latin America Digital Ad Spending 2019: As More Consumers Turn to Digital, Ad Spending Grows”, eMarketer, marzo 2019.

Véase Ceurvels, M, "Digital Ad Spending in Latin America Is Growing Despite Market Volatility", eMarketer, julio 2020, https://www.emarketer.com/content/digital-ad-spending-latin-america-growing-despite-market-volatility

23 De acuerdo a estimaciones más recientes de eMarketer, se espera que la publicidad total sufra la mayor caída del mundo en la región en 2020- un 10\%-aunque, por el contrario, la publicidad digital tendrá la mejor performance global,creciendo un 5\%. Véase: https://www.emarketer.com/content/latam-traditional-ad-spending-will-crater-digital-ad-spending-will-spike

t24 Véase Internet WorldStats 2020.), y a la aún fuerte presencia de la TV tradicional (Ceurvels 2019; Arthur D. Little 2018

La industria de la música puede servir de espejo para entender la transición hacia un nuevo modelo que están viviendo los medios de noticias y que muy probablemente le haga retomar su crecimiento. La aparición del MP3 y los sistemas de intercambio P2P golpeó los ingresos musicales entre 2001 y 2010 con una caída del $60 \%$. Sin embargo, durante ese mismo periodo las ventas digitales comenzaron a crecer sostenidamente gracias al streaming. El cambio de estrategia de la industria se hizo patente en 2014, con el modelo de suscripción liderando

125 ventas digitales comenzaron a crecer sostenidamente gracias al streaming. El cambio de estrategia de la industria se hizo patente en 2014, con el modelo de suscripción liderando crecimientos de más del $30 \%$ de sus ingresos año a año y más que compensando las caídas de ventas físicas y de descargas. Latinoamérica ha sido la región de más alto crecimiento en
streaming (IFPI 2019). En este caso se ve que hubo básicamente una sustitución de modelos, y que la industria necesitó un tiempo para adaptarse a las innovaciones y los nuevos modelos streaming (IFPI 2019). En este caso se ve que hubo

El término "adecuado" tiene un carácter subjetivo y del cual no hay precisamente un consenso si es que cubra los costos o financie nuevos proyectos o el subsistir familiar por $\mathrm{X}$ años, sin embargo, es el argumento utilizado por las SGC de derechos para solicitar mayores remuneraciones.

27 La CISAC está formada por 239 sociedades de autores, también conocidas como SGC que cubren repertorios audiovisuales, dramático, literatura, música y artes visuales. Por lo general estas SGC son organizaciones sin fin de lucro, dirigidas y controladas por sus miembros. 
Véase Susan Wojcicki YouTube blog personal, https://blog.youtube/news-and-events/youtube-at-15-my-personal-journey

Véase "Latin America SVOD subscriptions to double in 2025", SeñalNews, 16 de marzo de 2020, https://senalnews.com/en/research/latin-america-svod-subscriptions-to-double-in-2025

30 Véase Resultados Financieros de Spotify Technology S.A. del primer trimestre de 2020, 29 de abril 2020

https://investors.spotify.com/financials/press-release-details/2020/Spotify-Technology-SA-Announces-Financial-Results-for-First-Quarter-2020/default.aspx

De hecho, algunos estudios y encuestas marcan un descenso de la piratería, como el estudio global de piratería digital de la Universidad de Amsterdam o el "Observatorio de la piratería y

hábitos de consumo de contenidos digitales 2018" de España, https://www.ivir.nl/publicaties/download/Global-Online-Piracy-Study.pdf y

http://lacoalicion.es/wp-content/uploads/ndp.-observatorio-pirateria 2018 5-abril.pdf

32 Red/Acción hasta señala en su decálogo de principios que "la publicidad está muerta" y se promueve un periodismo con propósito y humano por sobre la "infoxicación" ofreciendo productos digitales (web, newsletters, redes sociales y LAB) pero también recurriendo al papel para su revista.

33 En el trabajo "El periodismo por los periodistas: Perfiles profesionales en las democracias de América Latina"

33 https://www.kas.de/c/document_library/get_file?uuid=ef1da7ad-6f7a-835e-33bb-41a0798a6885\&groupId=252038

34 Véase, por ejemplo, demandas de la organización Derechos Digitales: https://www.derechosdigitales.org/11078/los-bloqueos-de-internet-y-la-defensa-de-la-democracia/

Véase, por ejemplo, documento "Aportes para una regulación democrática de las grandes plataformas que garantice la libertad de expresión en Internet", marzo de 2019,

https://www.observacom.org/observacom-adc-e-intervozes-proponen-una-nueva-perspectiva-regulatoria-para-enfrentar-el-creciente-poder-de-las-grandes-plataformas-de-internet/

36 Un jardín vallado (del término walled garden en inglés) es una analogía utilizada en el caso de medios o plataformas que ejercen el control sobre las aplicaciones o el contenido disponible En general, se refiere a la imposibilidad de los usuarios de acceder a toda la información de un determinado servicio.

†37 Véase Digital 2019: Q3 Global Digital Statshot, 17 de julio de 2019

Por otra parte, un escenario de límites al intercambio y difusión de información de medios en internet puede fomentar campañas de desinformación y la circulación de las llamadas "noticias falsas", al dificultar el acceso a puntos de validación públicos. En la misma línea, las iniciativas de fact-checking se verían afectadas en su capacidad de encontrar información para confirmar o refutar este tipo de publicaciones.

Son mecanismos y procedimientos establecidos en la carta de la Organización de Estados Americanos y otros instrumentos jurídicos como la Convención Americana de Derechos Humanos. Se conforma por la Comisión Interamericana de Derechos Humanos y la Corte Interamericana de Derechos Humanos.

140 Véase "Facebook users are uploading 350 million new photos each day", Business Insider, 2013, : https://www.businessinsider.com/facebook-350-million-photos-each-day-2013-9

141 Véase "Twitter by the numbers: Stats, Demographics \& Fun Facts, 2020: https://www.omnicoreagency.com/twitter-statistics/

Por ejemplo, si existieran exenciones o previsiones de llevar adelante este control y pago del derecho de autor que beneficien a entidades de menor escala u ONGs, sería de esperarse que en la práctica ellas puedan servir para que empresas enmascaren su fin de lucro o sub-declaren ingresos y así quedar por debajo del monto mínimo para ser sujetos pasivos de las obligaciones. De igual modo, en tanto la actividad online puede tener fronteras jurisdiccionales borrosas y sufrir limitaciones sobre el control y competencias regulatorias, la implantación medidas sin una lógica funcional práctica en una región como América Latina puede dar lugar a actitudes distorsivas.

†43 Véase por ejemplo OCDE 2018

144 Véase CEPAL (2019)

45 Véase CMA (2020).

146 Véase The Economist "Dismembering Big Tech", 24 de octubre de 2019.

Véase "Connected Society: Contenido en América Latina, la importa relevante es el que combina idioma, relevancia y creación local.

Comprende las regalías y tarifas de licencia son pagos y cobros entre residentes y no residentes por el uso autorizado de activos intangibles, no financieros, no fabricados, y derechos de 48 propiedad (como patentes, derechos de autor, marcas registradas, procesos industriales y franquicias) y por el uso, en virtud de contratos de licencia, de originales producidos de prototipos (como peliculas y manuscritos).

49 Para mayor detalle de cómo funciona Content ID, veáse por ejemplo Ocampo Rey, Alvaro, "YouTubers: viviendo y sobreviviendo al Copyright", Revista "mi patente" 22 de julio de 2016 https://www.mipatente.com/youtubers-viviendo-y-sobreviviendo-al-copyright/

t50 Véase 2020 LAVCA Industry Data \& Analysis, https:/lavca.org/industry-data/2020-industry-data-analysis/

La popularidad de los jugadores en tanto "influencers" ha beneficiado a la industria a través de un canal de "marketing no tradicional" lo cual ha promovido una "convivencia pacífica" de desarrolladores, marcas anunciantes, inversores y sponsors y jugadores Mantegna (2017). De todos modos, es de esperarse que esta situación de "convivencia pacífica de derechos no exigidos" se mantendrá en tanto la industria siga creciendo.

52 Véase José Luis Urbina Bustios: Los Videojuegos No Son Un Juego Los Desconocidos Éxitos de Los Estudios de América Latina y El Caribe. Una revisión del uso de los videojuegos con fines educativos, octubre 2019 .

t53 Véase anuncio oficial del 16 de julio de 2018 y fallo de la CNDC.

154 Ver: https://twitter.com/AxelKuschevatzk/status/1262174391774769152.

†5 Véase GSMA. 2019. The Mobile Economy 2019. https://www.gsma.com/mobileeconomy/ 